\title{
Regionalism and Multilateral Tariff Cooperation
}

\author{
by \\ Kyle Bagwell, Columbia University \\ Robert Staiger, University of Wisconsin-Madison
}

December 1996

Discussion Paper Series No. 9697-09

$$
\begin{aligned}
& \text { dp 9697-09 } \\
& \text { pages: } 40
\end{aligned}
$$




\title{
REGIONALISM AND MULTILATERAL TARIFF COOPERATION*
}

\author{
by \\ Kyle Bagwell and Robert W. Staiger
}

Revised: December 1996

*Bagwell: Northwestern University; Staiger: The University of Wisconsin-Madison and NBER. For helpful comments, we thank Martin Richardson (our discussant), an anonymous referee, John Piggott and Alan Woodland (the conference organizers), Nina Watts (the conference editor), and the conference participants. This paper was completed while Staiger was a Fellow at the Center for Advanced Study in the Behavioral Sciences. Staiger is also grateful for financial support provided by The National Science Foundation Grant \# SBR-9022192. 


\begin{abstract}
We consider a three-country world in which each country's import market is served by competing exporters from its two trading partners. We assume that weak multilateral enforcement mechanisms prevent governments from implementing efficient trade policies through a multilateral agreement that requires tariffs to conform to the most-favored-nation (MFN) principle. We then ask whether exceptions from MFN for the purpose of forming preferential agreements can lead to lower external tariffs, and thereby to a more efficient tariff structure under the multilateral agreement. We identify three opposing effects of preferential agreements on the multilateral tariff structure in this setting. A first effect, the tariff complementarity effect, works to reduce the desired external tariffs of countries that join together in a preferential agreement. Two additional effects of preferential agreements arise only when enforcement issues at the multilateral level are considered. One of these, the punishment effect, weakens the ability of the member countries of a preferential agreement to punish deviations from the multilateral agreement, thereby interfering with the ability of countries to sustain low tariffs under the multilateral agreement. The other of these, the tariff discrimination effect, allows countries to discriminate against those who would "free ride" under MFN, and therefore works to increase the desired external tariffs of countries that join together in a preferential agreement. The relative strengths of these three effects determine the impact of a preferential agreement on the tariff structure under the multilateral agreement. Our findings suggest that preferential agreements can have their most desirable effects on the multilateral system when the degree of multilateral cooperation is low.
\end{abstract}




\section{Introduction}

In recent years, there has been a proliferation of regional trading agreements. What are the consequences of such agreements for multilateral tariff cooperation? Are regional agreements "building blocks" or "stumbling blocks" for the multilateral liberalization process? In this paper, we develop a formal model that identifies important effects that regional agreements may have for multilateral tariff cooperation. We find that the consequences of regional agreements for multilateral tariff cooperation need not be clear cut: Effects exist under which regional agreements complement multilateral liberalization efforts, and effects also exist under which regional agreements undermine the multilateral liberalization process. While we do not provide a conclusive answer to the questions posed above, we outline a framework of effects with which to better understand the possible impact of regional agreements for multilateral tariff cooperation. We also describe circumstances in which the net impact of the various effects can be determined.

We present our results in a "competing exporters" model of trade. There are three goods and three countries, and each country imports one good that is supplied by each of the other two countries. We consider first a static model of trade, in which we allow that two of the countries enter into regional trading agreements. Here, we identify a tariff complementarity effect: When the two countries reduce their tariffs to zero on one another, they each find it attractive to lower as well the tariff applied to the imports from the non-member country. In the static model, therefore, regional agreements complement multilateral liberalization efforts. We show further that the extent of multilateral liberalization is higher if the regional agreement takes the form of a free-trade agreement than when the regional agreement takes the form of a customs union.

While the static model serves to illustrate the tariff complementarity effect, we argue that international trade agreements are best modeled as the outcome of a repeated game. The repeated-game approach puts enforcement at center stage. Can countries use the threat of a trade war to enforce lower multilateral tariffs when regional agreements have taken place? To explore this question, we begin with the benchmark case in which no regional agreements have taken place and countries adopt most favored nation (MFN), i.e., non-discriminatory, tariffs. We allow that two of the countries are patient and thus willing to cooperate at very low tariffs, whereas the third country is less patient and unable to sustain reciprocal tariff reductions below a certain level. In this setting, we find that the former two countries act as hegemons (see, for example, 
Kindleberger, 1981), eventually offering to lower their tariffs to a degree greater than they request reciprocally from the impatient country. This is because, when tariffs are non-discriminatory, the patient countries can achieve further bilateral liberalization only if they also offer further multilateral liberalization. Accordingly, the MFN principle may benefit "weak" countries that can not sustain deep liberalization, since such countries are eventually allowed to partially "free ride" on the liberalization activities of other countries.

We consider next the possibility that the two patient countries form a free-trade area. An understanding of the consequences of this regional agreement for the multilateral tariffs that are associated with the third country is facilitated with the identification of three key effects. First, as in the static game, there is a tariff complementarity effect: When two countries form a free-trade area, they are attracted to lower tariffs on imports from non-members. As before, this effect suggests that regional agreements complement multilateral tariff cooperation. A second effect is a punishment effect, which is actually the flip-side of the tariff complementarity effect. In particular, since the members of the free-trade area find high multilateral tariffs unattractive, the threat of a trade war from such a region is not especially worrisome, and so the non-member country is less able to sustain a low multilateral tariff on its imports once the other countries have formed a free-trade area. The punishment effect, therefore, suggests that the formation of a free-trade area may harm multilateral tariff cooperation. Finally, a third effect is the discrimination effect. This effect describes the free-rider benefits of MFN liberalization that the impatient country loses once the patient countries form a free-trade area and select discriminatory tariffs. This effect suggests that regional agreements undermine multilateral tariff cooperation.

We demonstrate that the three effects can be ranked when the non-member country is sufficiently impatient. In that event, the non-member country is focused on the present, and the punishment effect is eliminated. The tariff complementarity and discrimination effects remain, however, and the latter will dominate if and only if the two member countries are sufficiently patient, so that their multilateral liberalization under MFN is sufficiently deep. In this case, the formation of a free-trade area leads to an overall deterioration in multilateral tariff cooperation.

Finally, we consider the case of customs union formation, finding that the same three effects appear. With customs union, the tariff complementarity and punishment effects are weakened, however, since a member of a customs union is less attracted to low multilateral tariffs 
than is a member of a free-trade area. When the non-member country is sufficiently impatient, so that the punishment effect is eliminated, we find again that the discrimination effect dominates if and only if the two member countries are sufficiently patient. In this circumstance, the formation of a customs union results in an overall deterioration in multilateral tariff cooperation. Furthermore, we find that customs union formation is more likely to harm multilateral tariff liberalization than is free-trade area formation, in that the former leads to increased multilateral tariffs from member countries for a wider range of patience levels for the member countries.

Our paper contributes to a growing literature concerned with the impact of regional agreements on the multilateral trading system. For example, Richardson $(1992,1993)$ argues that the formation of free trade agreements can initiate a competition for tariff revenue that leads member countries to reduce their external tariffs. Focussing on enforcement issues at the multilateral level, Bond and Syropoulos (1993) argue that customs union formation may make low multilateral tariffs more difficult to sustain. Bond, Syropoulos, and Winters (1995) show that the deepening of regional integration within a customs union can enhance the ability of the multilateral agreement to secure low multilateral tariffs. Bagwell and Staiger (1996a, 1996b) focus on the period of transition during which regional agreements are formed, and show that the formation of customs unions is likely to lead to a temporary "honeymoon" period of enhanced multilateral cooperation, while the formation of free trade agreements is more apt to bring discord at the multilateral level. The present paper contributes to this literature by identifying several new effects of regional agreements that have not previously been analyzed, and by exploring their implications for the enforcement of multilateral tariff cooperation.

\section{The Static Model}

We consider a three-country three-good partial equilibrium world in which each country's import market is served by competing exporters from its two trading partners. The three countries are denoted by $\mathrm{A}, \mathrm{B}$, and $\mathrm{C}$, and we use $\mathrm{J}=\{\mathrm{A}, \mathrm{B}, \mathrm{C}\}$ as a notational index for countries. In similar fashion, the three goods are represented as $a, b$, and $c$, and we use $i=\{a, b, c\}$ as our notational index for goods. Finally, it is sometimes convenient to let $\mathrm{j}$ identify the good that corresponds to the lower case value of $J$ (e.g., if $J=A$, then $j=a$ ). We assume that country $J$ is endowed with zero units of good $j$, while it is endowed with $3 / 2$ units of each of the other two goods. Country 
$\mathrm{J}$ demands each of the three goods, however, and the demand for good i in country $\mathrm{J}$ is given by $D\left(P_{i}^{J}\right)=\alpha-\beta P_{i}^{J}$, with $P_{i}^{J}$ denoting the price of good $\mathrm{i}$ in country $\mathrm{J}$. Thus, country $\mathrm{J}$ must import good $\mathrm{j}$ to consume it, and can import good $\mathrm{j}$ from either trading partner.

Given the symmetry of the world as viewed from any one country, we can economize on the presentation of the static model by letting $L(J)$ denote $J$ 's "left-hand" trading partner and $R(J)$ denote $J$ 's "right-hand" trading partner. We then use $1(J)$ to denote the good that $J$ exports to its left-hand trading partner, and we let $r(J)$ represent the good that $J$ exports to its right-hand trading partner. Figure 1 illustrates the trading relationships as viewed by country $\mathrm{A}$ using this notation (i.e., for $J=A$ ). Here, country A's left-hand trading partner is country $B$ (i.e., $B=L(A)$ ), and country A exports good b to country B (i.e., $b=l(A)$ ).

As Figure 1 makes clear, we do not allow a country to simultaneously import a good from one source and export it to another. Given the symmetry of the model, this practice would never occur if tariffs satisfy the most-favored-nation (MFN) principle and hence were nondiscriminatory. In principle, however, it is possible that the tariff discrimination that emerges when countries enter into regional agreements could induce exporters to begin serving new markets that they heretofore had found unprofitable. In our analysis of regional agreements, we abstract from this possibility. We do so for two reasons. First, in practice, there are likely to be fixed costs associated with serving a new market, and so the corresponding new trading volume would need to be significant before such costs would be incurred. Second, this abstraction greatly simplifies the analysis, enabling us to offer a tractable framework within which to isolate and study important effects of regional agreements for multilateral tariff cooperation.

With this notation we let $\tau_{j}^{L(J)}$ denote country J's specific tariff on imports of $j$ from its left-hand trading partner. Analogously, we denote country J's specific tariff on imports of good $\mathrm{j}$ from its right-hand trading partner by $\tau_{j}^{R(J)}$, and we denote by $\tau_{I(J)}^{J}$ and $\tau_{r(J)}^{J}$ the specific tariffs faced by country J's exporters from its left-hand and right-hand trading partners, respectively. ${ }^{1}$ Focussing on tariffs that are non-negative and non-prohibitive to bilateral trade

\footnotetext{
${ }^{1}$ Thus, for tariffs, the superscript refers to the country to whom the tariff is applied, whereas the subscript identifies the import good and thereby the importing country.
} 
flows, we have the following arbitrage conditions relating the price of good $\mathrm{j}$ in importing country $J$ and exporting countries $L(J)$ and $R(J)$ :

$$
P_{j}^{J}=P_{j}^{L(J)}+\tau_{j}^{L(J)}=P_{j}^{R(J)}+\tau_{j}^{R(J)}, \quad J=\{A, B, C\} .
$$

Import and export functions can also be defined as

$$
M_{j}\left(P_{j}^{J}\right)=D\left(P_{j}^{J}\right) ; \quad X_{i(U)}^{J}\left(P_{i(U)}^{J}\right)=3 / 2-D\left(P_{i(J)}^{J}\right), \quad i=\{1, r\},
$$

respectively. ${ }^{2}$ Finally, the market clearing conditions are given by

$$
M_{j}\left(P_{j}^{J}\right)=X_{j}^{L(J)}\left(P_{j}^{L(J)}\right)+X_{j}^{R(J)}\left(P_{j}^{R(J)}\right) .
$$

Using the arbitrage conditions in (1), the market clearing conditions in (2) can be solved to yield equilibrium prices in each country as a function of the chosen tariffs:

$$
\begin{aligned}
& P_{j}^{J}\left(\tau_{j}^{L(J)}, \tau_{j}^{R(J)}\right)=(\alpha-1) / \beta+\left(\tau_{j}^{L(J)}+\tau_{j}^{R(J)}\right) / 3 ; \\
& P_{i(J)}^{J}\left(\tau_{i(J)}^{J}, \tau_{i(J)}^{I(J)}\right)=\{\alpha-1) / \beta-\left(2 \tau_{i(J)}^{J}-\tau_{i(J)}^{I(J)}\right) / 3, \quad(I, i) \in\{(R, I),(L, r)\} .
\end{aligned}
$$

Hence, as (3) indicates, the price in country $\mathbf{J}$ of import good $\mathrm{j}$ is increasing in $\mathbf{J}$ 's tariff on imports from each of its trading partners. As for export goods, the price in country $\mathrm{J}$ of the good $1(\mathrm{~J})$ that $\mathrm{J}$ exports to its left-hand trading partner is decreasing in the tariff faced by its exporters and increasing in the tariff imposed on competing exports of $1(\mathrm{~J})$ coming from J's right-hand trading partner. Similar remarks apply for good $\mathrm{r}(\mathrm{J})$.

Market clearing trade volumes are now given by:

$$
\begin{aligned}
& M_{j}\left(\tau_{j}^{L(J)}, \tau_{j}^{R(J)}\right)=1-\beta\left(\tau_{j}^{L(J)}+\tau_{j}^{R(J)}\right) / 3 ; \\
& X_{i(J)}^{J}\left(\tau_{i(J)}^{J}, \tau_{i(J)}^{I(J)}\right)=1 / 2-\beta\left(2 \tau_{i(J)}^{J}-\tau_{i(J)}^{I(J)}\right) / 3, \quad(I, i) \in\{(R, I),(L, r)\} .
\end{aligned}
$$

As expected, country J's import volume is decreasing in the import tariff that it selects for good $\mathrm{j}$, and similarly country J's export volume of good $1(J)$ is decreasing in the import tariff levied

\footnotetext{
${ }^{2}$ We suppress country superscript on the import function $M_{j}\left(P_{j}^{J}\right)$ as only one country imports each good. We include country superscript on the export functions $X_{i(J)}^{J}\left(P_{i(J)}^{J}\right) \mathrm{i}=\{1, \mathrm{r}\}$ as each good is exported by two countries.
} 
upon this export good by country L(J). Notice further that country J's export volume of good l(J) increases when country $L(J)$ applies a higher tariff to the competing exporters in country $R(J)$. A similar interpretation applies to good $r(J)$. Finally, using (4) we have that tariffs will be nonprohibitive provided that

$$
3 / 4 \beta+\tau_{I(J)}^{R(J)} / 2>\tau_{I(J)}^{J} ; 3 / 4 \beta+\tau_{Y(J)}^{L(J)} / 2>\tau_{r(J)}^{J}, \text { for } J=\{A, B, C\} .
$$

We define welfare of each country as the sum over each good of consumer surplus, producer surplus, and tariff revenue. With the functional dependence of market clearing prices and trade volumes on tariffs given in (3) and (4), respectively, country J's welfare is given by:

$$
\begin{gathered}
W^{J}\left(\tau_{j}^{L(J)}, \tau_{j}^{R(J)} ; \tau_{I(J)}^{J}, \tau_{I(J)}^{R(J)} ; \tau_{r(J)}^{J}, \tau_{r(J)}^{L(J)}\right)=\int_{P_{j}^{J}}^{\alpha / \beta} D(P) d P+\int_{P_{I(J)}^{J}}^{\alpha / \beta} D(P) d P+\int_{P_{I(J)}^{J}}^{\alpha / \beta} D(P) d P \\
+3 P_{I(J)}^{J} / 2+3 P_{r(J)}^{J} / 2+\tau_{j}^{L(J)} X_{j}^{L(J)}+\tau_{j}^{R(J)} X_{j}^{R(J)} .
\end{gathered}
$$

The qualitative features of our results are unaltered if the producer-surplus terms are scaled with parameters representing political-economy considerations (Bagwell and Staiger, 1996c).

With government welfare functions now defined, we first solve for the Nash tariff choices of countries A, B, and C. Our partial equilibrium structure and our assumption that countries do not tax exports imply that each country's optimal tariff choices will be independent of those of its trading partners. However, we now show that a country's choice of tariff on imports from its left-hand trading partner will depend on the tariff it sets on imports of the same good from its right-hand trading partner. The first-order conditions that define country J's best-response tariffs on imports of good $\mathrm{j}$ from its left- and right-hand trading partner, denoted by $\tau_{j}^{L(J)}\left(\tau_{j}^{R(J)}\right)$ and $\tilde{\tau}_{j}^{R(J)}\left(\tau_{j}^{L(J)}\right)$, respectively, are given by

$$
\begin{aligned}
& \partial W^{J} / \partial \tau_{j}^{L(J)}=0 \quad \Rightarrow \quad \tilde{\tau}_{j}^{L(J)}\left(\tau_{j}^{R(J)}\right)=3 / 22 \beta+7 \tau_{j}^{R(J)} / 11, \\
& \partial W^{J} / \partial \tau_{j}^{R(J)}=0 \quad \Rightarrow \quad \tilde{\tau}_{j}^{R(J)}\left(\tau_{j}^{L(J)}\right)=3 / 22 \beta+7 \tau_{j}^{L(J)} / 11 .
\end{aligned}
$$

It is straightforward to check that second-order conditions are globally met.

Condition (6) reveals an interesting complementarity between a country's tariffs on imports 
of the same good from different trading partners. As the tariff on imports of $j$ from J's right-hand trading partner rises, it becomes more attractive for $J$ to raise the tariff on imports of $j$ from its left-hand trading partner. The complementarity of import tariffs across trading partners reflects three reinforcing effects. First, with $\tau_{j}^{R(J)}$ higher, the volume of J's consumption of good j drops, and so the consumer surplus cost of the price increase associated with a rise in $\tau_{j}^{L(J)}$ is lower. Second, with $\tau_{j}^{R(J)}$ higher, imports from $\mathrm{L}(\mathrm{J})$ rise, and so the increase in tariff-revenue collected on imports from $L(J)$ as $\tau_{j}^{L(J)}$ rises is larger. And third, with $\tau_{j}^{R(J)}$ higher, the increase in imports from $\mathrm{R}(J)$ that comes with a rise in $\tau_{j}^{L(J)}$ generates a greater increase in tariff revenue. Therefore, as (6) indicates, higher import tariffs on one import source will encourage a choice of higher import tariffs on competing import sources.

Finally, it is direct to solve (6) for the Nash equilibrium tariffs. Exploiting the symmetry of the model, we set $\tau_{j}^{L(J)}=\tau_{j}^{R(J)}$ to find $\tau^{N=3 / 8 \beta}$. From (5), symmetric tariffs in excess of $3 / 2 \beta$ are required to prohibit trade, and so the unique symmetric Nash equilibrium has each country setting a non-prohibitive tariff $\tau^{\mathrm{N}}$ on imports from each trading partner.

As for the efficiency properties of the Nash equilibrium, it is straightforward to show that a country's welfare is negatively affected by a tariff on its exports (its terms of trade worsen), but positively effected by a tariff on its competitor's exports (its terms of trade improve). Nevertheless, the overall impact of an importing country's tariffs on exporting country welfare is negative, and hence each country's tariffs exert a negative externality on all its trading partners taken together. As such, from an efficiency point of view (maximizing the sum of $\mathrm{W}^{\mathrm{A}}, \mathrm{W}^{\mathrm{B}}$, and $\mathrm{W}^{\mathrm{C}}$ ), the Nash equilibrium involves too much protection and, indeed, efficiency requires free trade. Hence, countries face a Prisoner's Dilemma problem due to the terms-of-trade externalities associated with their tariff choices.

We complete this section by considering the impact of regional agreements on external tariffs in the Nash equilibrium. In so doing, we illustrate a tariff complementarity effect that regional liberalization will have on desired external tariff levels in the Nash equilibrium. This effect will play an important role in the following section, where we explore more fully the implications of regional agreements for multilateral tariff cooperation. 
Consider first the impact of a free trade agreement between countries $\mathrm{A}$ and $\mathrm{B}$ on the external tariffs chosen by countries $\mathrm{A}, \mathrm{B}$, and $\mathrm{C}$ in the Nash equilibrium. Under a free trade agreement between $\mathrm{A}$ and $\mathrm{B}$, we set $\tau_{a}^{B}=\tau_{b}^{A}=0$. However, countries $\mathrm{A}$ and $\mathrm{B}$ continue to set their remaining tariffs independently to maximize their respective welfare while county $\mathrm{C}$ continues to set tariffs on imports from A and B to maximize its welfare. By condition (6), country C's tariff choices are independent of those of its trading partners, and so $\mathrm{C}$ continues to set tariffs given by $\tau_{C}^{A}=\tau_{c}^{B}=\tau^{N}=3 / 8 \beta$. However, country A chooses its optimal tariff on imports from $\mathrm{C}$ given its free trade agreement with $B$, which by (6) is given by $\tilde{\tau}_{a}^{C}\left(\tau_{a}^{B}=0\right)=3 / 22 \beta \equiv \tilde{\tau}<\tau^{N}$. Similarly, country B chooses its optimal tariff on imports from $\mathrm{C}$ given its free trade agreement with $\mathrm{A}$, which by (6) is given by $\tilde{\tau}_{b}^{C}\left(\tau_{b}^{A}=0\right)=3 / 22 \beta \equiv \tilde{\tau}<\tau^{N}$. Comparing multilateral tariffs in the presence of a free trade agreement between A and B to multilateral tariffs in the absence of such an agreement, we therefore find that C's tariff choices are unaffected by the agreement between $\mathrm{A}$ and $\mathrm{B}$ but that $\mathrm{A}$ and $\mathrm{B}$ choose to liberalize their external tariffs as a result of the free trade agreement between them. This reflects the tariff complementarity effect that regional liberalization has on desired external tariff levels in the Nash equilibrium: Countries that eliminate tariffs against imports from a subset of their trading partners through a free trade agreement will be inclined in a Nash equilibrium to reduce external tariffs against their remaining trading partners as well. ${ }^{3}$

Finally, we observe that the tariff complementarity effect of a free trade agreement is strong enough to ensure that $C$ gains in the Nash equilibrium when $A$ and $B$ form a free trade agreement relative to its Nash welfare absent a free trade agreement. Such an outcome is not ensured, since the free trade agreement between $\mathrm{A}$ and $\mathrm{B}$ has two opposing effects on $\mathrm{C}$ : given the tariff complementarity effect it ensures that C's exports are taxed less, but the agreement also

\footnotetext{
${ }^{3}$ This effect is reminiscent of an observation made by Richardson (1992), but occurs for different reasons and under different trading patterns. Richardson considers free trade agreements between countries that are competing importers of a common good from third countries, and argues that in these circumstances each partner in the agreement will have an incentive to lower its external tariff to slightly below the external tariff of the other partners so as to increase its share of tariff revenue collected on imports from outside the free trade area. We focus, by contrast, on free trade agreements between countries that are competing exporters of a common good to third countries, but that do not compete for imports of a common good from third counties.
} 
implies that the exporters in A and B with which C's exporters compete face no tax. However, defining $\Delta W_{F T A}^{C}$ as the change in C's welfare under the Nash equilibrium following the creation of a free trade agreement between $\mathrm{A}$ and $\mathrm{B}$, it is straightforward to show that

$$
\Delta W_{F T A}^{C} \equiv W^{C}\left(\tau^{N}, \tau^{N} ; \tilde{\tau}, 0 ; \tau, 0\right)-W^{C}\left(\tau^{N}, \tau^{N} ; \tau^{N}, \tau^{N} ; \tau^{N}, \tau^{N}\right)>0
$$

Hence, the outside country gains when its trading partners form a free trade agreement.

Consider next the impact of a customs union between countries $\mathrm{A}$ and $\mathrm{B}$ on the external tariffs chosen by countries A, B, and C in the Nash equilibrium. Under a customs union between $\mathrm{A}$ and $\mathrm{B}$, we set $\tau_{a}^{B}=\tau_{b}^{A}=0$. However, countries $\mathrm{A}$ and $\mathrm{B}$ now set their remaining tariffs to maximize their joint welfare, while county $\mathrm{C}$ continues to set tariffs on imports from $\mathrm{A}$ and $\mathrm{B}$ to maximize its welfare. Notice that countries A and B do not import a common good, and so the customs union does not impose a direct constraint on each member's external tariff choices, i.e., these choices need not be harmonized. However, external tariff choices are nonetheless affected by the joint welfare criterion adopted under a customs union.

Again, by condition (6), country C's tariff choices are independent of those of its trading partners, and so $C$ continues to set tariffs given by $\tau_{c}^{A}=\tau_{C}^{B}=\tau^{N}=3 / 8 \beta$. However, country A chooses its optimal tariff on imports from $\mathrm{C}$, given its customs union with $\mathrm{B}$, to maximize $\mathrm{W}^{\mathrm{A}}+\mathrm{W}^{\mathrm{B}}$, the joint welfare of $\mathrm{A}$ and $\mathrm{B}$. Country $\mathrm{B}$ chooses its optimal tariff on imports from $\mathrm{C}$ analogously. Defining $\bar{\tau}_{a}^{C}\left(\tau_{a}^{B}\right) \quad\left(\bar{\tau}_{b}^{C}\left(\tau_{b}^{A}\right)\right)$ as the tariff on A's (B's) imports from $\mathrm{C}$ that maximizes the joint welfare of $\mathrm{A}$ and $\mathrm{B}$, the first order conditions for these problems yield $\bar{\tau}_{a}^{C}\left(\tau_{a}^{B}=0\right)=\bar{\tau}_{b}^{C}\left(\tau_{b}^{A}=0\right)=3 / 10 \beta \equiv \bar{\tau}<\tau^{N}$. Hence, as with a free trade agreement, a customs union exhibits a tariff complementarity effect which leads countries A and B to lower their Nash tariffs against $\mathrm{C}$.

However, the tariff complementarity effect is weaker in a customs union than it is in a free trade agreement, and we have $\tilde{\tau}<\bar{\tau}<\tau^{N}$. This is because members of a customs union are concerned about the negative externality imposed on other customs union members when they lower their external tariff and thereby reduce the tariff advantage offered to their customs union partners. Moreover, the tariff complementarity effect is sufficiently weakened under a customs 
union that $\mathrm{C}$ no longer gains relative to the Nash equilibrium with no agreement between $\mathrm{A}$ and B. Defining $\Delta w_{C U}^{C}$ as the change in C's welfare under the Nash equilibrium following the creation of a customs union between $\mathrm{A}$ and $\mathrm{B}$, it is straightforward to show that

$$
\Delta W_{C U}^{C} \equiv W^{C}\left(\tau^{N}, \tau^{N} ; \bar{\tau}, 0 ; \bar{\tau}, 0\right)-W^{C}\left(\tau^{N}, \tau^{N} ; \tau^{N}, \tau^{N} ; \tau^{N}, \tau^{N}\right)<0 .
$$

Unlike the case of a free trade agreement, we find that the tariff complementarity effect under a customs union is therefore too weak to outweigh the negative effects of tariff discrimination on the outside country, who loses due to the tariff discrimination it now faces in serving the markets of the customs union.

The tariff complementarity effect associated with regional agreements that we have identified above suggests that regional agreements might be thought of as complementary to multilateral liberalization or, in Bhagwati's (1991) terminology, as building blocs rather than stumbling blocs to multilateral liberalization. However, we have maintained throughout this section the assumption that multilateral tariffs are set non-cooperatively in a Nash equilibrium. Effectively, this ignores the fact that regional agreements are occurring within the broader context of attempts at multilateral cooperation. In the next section, we extend our analysis to incorporate this important dimension.

\section{Regionalism and Multilateral Tariff Cooperation}

In this section we consider the fact that regional agreements occur within the broader context of attempts to maintain multilateral tariff cooperation. This requires that we acknowledge efforts to cooperate in tariff policy at the multilateral level. However, if these multilateral efforts were perfect in the sense that they implemented efficient trade policies from the perspective of countries A, B, and C, then free trade at the multilateral level would be achieved and there would be no role for regional agreements. Therefore, we must introduce a reason why multilateral cooperation is limited.

Here we focus on enforcement difficulties at the multilateral level as a reason why the multilateral agreement can not achieve full efficiency. In particular, we adopt the view that the multilateral agreement must be self-enforcing (see, for example, Dam, 1970), and model 
multilateral tariff cooperation as a repeated game among the three countries. The repeated game that we consider involves infinite repetition of the static game developed in the previous section. The three countries attempt to achieve tariffs below their static Nash levels and use infinite reversion to the static Nash tariffs as a credible (subgame perfect) punishment that would be triggered if any country were to defect from its stipulated tariffs under the multilateral agreement. In this setting, we assume that limits to multilateral enforcement prevent the multilateral agreement from reaching global free trade. We then ask how preferential agreements affect the ability of countries to sustain low multilateral tariffs.

We proceed in three stages. First we consider the ability of countries to achieve low nondiscriminatory tariffs. That is, we look for the lowest (non-negative) tariffs achievable by the multilateral agreement under the restriction that all tariffs conform to the most-favored-nation (MFN) principle. This provides a multilateral benchmark from which to gauge the impacts of regional agreements on multilateral cooperation. Next, we consider how the degree of multilateral tariff cooperation is affected by the presence of a free trade agreement between countries A and B. And finally, we consider how the presence of customs unions affects the degree of multilateral tariff cooperation.

\section{III.A MFN}

We begin by considering the ability of countries $\mathrm{A}, \mathrm{B}$, and $\mathrm{C}$ to maintain low multilateral tariffs under the restriction that all tariffs conform to the most-favored-nation (MFN) principle.

The principle of MFN requires that $\tau_{j}^{L(J)}=\tau_{j}^{R(J)} \equiv \tau_{j}$ for $\mathrm{J}=\{\mathrm{A}, \mathrm{B}, \mathrm{C}\}$. We assume that the three countries attempt to maintain low MFN tariffs $\left(\tau_{a}, \tau_{b}, \tau_{c}\right)$ with the threat of infinite reversion to the Nash tariff $\tau^{N}$ in the event that any country deviates from its tariff as stipulated under the agreement. To solve for the most-cooperative tariffs sustainable under the agreement, i.e., the self-enforcing tariffs that maximize the joint welfare of the three countries, we must consider the incentive constraints under which countries operate.

When each country's tariff policy conforms to MFN, we represent country J's welfare by

$$
\hat{W}^{J}\left(\tau_{j}, \tau_{I(J)}, \tau_{r(J)}\right) \equiv W^{J}\left(\tau_{j}, \tau_{j} ; \tau_{I(J)}, \tau_{I(J)} ; \tau_{r(J)}, \tau_{r(J)}\right)
$$

In developing the incentive constraints faced by each country, we consider first the one-time 
payoff to country $\mathbf{J}$ in deviating from the multilateral agreement. Since punishment from both trading partners will follow any deviation, we consider the one-time payoff to $\mathrm{J}$ in deviating simultaneously against both its trading partners to its best-response tariff $\tau^{N}$. Denoting this onetime payoff from defection by $\Omega\left(\tau_{j}, \tau_{1(J)}, \tau_{r(J)}\right)$, we note that

$$
\begin{aligned}
\Omega\left(\tau_{j}, \tau_{I(J)}, \tau_{r(J)}\right) & \equiv \hat{W}^{J}\left(\tau^{N}, \tau_{I(J)}, \tau_{r(J)}\right)-\hat{W}^{J}\left(\tau_{j}, \tau_{I(J)}, \tau_{r(J)}\right) \\
& =\frac{4 \beta}{9}\left[\tau_{j}-\tau^{N}\right]^{2} \equiv \Omega\left(\tau_{j}\right) .
\end{aligned}
$$

Observe that country $\mathbf{J}$ 's incentive to defect depends only upon the import tariff that country $\mathbf{J}$ selects under the multilateral tariff agreement. Not surprisingly, when country J selects a lower import tariff $\tau_{j}$ as part of the agreement, it has a correspondingly higher incentive to defect. At the other extreme, country J's incentive to defect is zero when it already sets its Nash tariff under the multilateral tariff agreement (i.e., when $\tau_{j}=\tau^{N}$ ).

Under the multilateral agreement, a deviation will be followed by infinite reversion to Nash tariffs for all countries. Thus, to see whether country $\mathrm{J}$ will indeed give in to the temptation to deviate as embodied in $\Omega\left(\tau_{j}\right)$, we next consider the cost of the ensuing "trade war." We represent the per-period cost of a trade war by $\hat{\omega}^{\mathcal{J}}\left(\tau_{j}, \tau_{I(\mathcal{J})}, \tau_{r(\mathcal{J})}\right)$, and note that

$$
\begin{aligned}
& \hat{\omega}^{J}\left(\tau_{j}, \tau_{I(J)}, \tau_{r(J)}\right) \equiv \hat{W}^{J}\left(\tau_{j}, \tau_{I(J)}, \tau_{r(J)}\right)-\hat{W}^{J}\left(\tau^{N}, \tau^{N}, \tau^{N}\right) \\
& \begin{aligned}
=\frac{1}{3}\left\{\beta\left(\tau^{N}\right)^{2}+\left[\frac{\beta}{6}(\right.\right. & \left.\left.\left.\left(\tau_{I(J)}\right)^{2}+\left(\tau_{r(J)}\right)^{2}\right)-\frac{1}{2}\left(\tau_{I(J)}-\tau_{r(J)}\right)\right]-\left[\frac{4 \beta}{3}\left(\tau_{j}\right)^{2}-\tau_{j}\right]\right\} \\
& \equiv \hat{\omega}\left(\tau_{j}, \tau_{I(J)}, \tau_{r(J)}\right) .
\end{aligned}
\end{aligned}
$$

This function exhibits several intuitive properties. In particular, country $\mathrm{J}$ experiences higher welfare under the agreement, and thus recognizes a higher per-period cost to a trade war, when its agreed-upon tariff is higher and when the agreed-upon tariff of any other country is lower. ${ }^{4}$

${ }^{4}$ This holds provided that country J's agreed-upon tariff is below the Nash level and that the tariffs of other countries do not exceed $3 / 2 \beta$ (so that trade is not prohibited). The effect of other countries' tariffs on country J's welfare may be understood in analogy with the reasoning developed above: When an importing country selects a lower MFN tariff, an exporting country experiences an overall increase in welfare, as the direct gain associated with the lower tariff on own exports exceeds the indirect loss associated with the lower tariff on competing exports. 
Also, when all countries select symmetric tariffs, the per-period cost of a trade war is maximized at free trade and is zero when the agreement itself calls for the Nash tariff.

Finally, to represent the discounted future cost that a country experiences when a trade war is initiated, we must describe the manner in which countries discount future welfare. We assume that countries are heterogenous in the degree to which they value the future, as embodied in each country's discount factor $\delta^{J} \epsilon[0,1)$. In particular, we assume that countries A and $\mathrm{B}$ are relatively patient as compared to country $\mathrm{C}$, so that

$$
\delta^{A}=\delta^{B}=\delta_{H} \geq \delta_{L}=\delta^{C} .
$$

We can now present the incentive constraints that must be satisfied for any set of MFN tariffs $\left(\tau_{a}, \tau_{b}, \tau_{c}\right)$ that are self-enforcing under the multilateral trade agreement. In particular, for each country, the one-time benefit in deviating from the agreement must be no greater than the discounted cost to that country of the ensuing trade war. Formally, we have:

$$
\begin{array}{ll}
\text { ICA: } & \Omega\left(\tau_{a}\right) \leq \frac{\delta_{H}}{1-\delta_{H}} \hat{\boldsymbol{\omega}}\left(\tau_{a}, \tau_{b}, \tau_{c}\right) \\
\text { ICB: } & \Omega\left(\tau_{b}\right) \leq \frac{\delta_{H}}{1-\delta_{H}} \hat{\omega}\left(\tau_{b}, \tau_{c}, \tau_{a}\right) \\
\text { ICC: } & \quad \Omega\left(\tau_{C}\right) \leq \frac{\delta_{L}}{1-\delta_{L}} \hat{\boldsymbol{\omega}}\left(\tau_{c}, \tau_{a}, \tau_{b}\right) .
\end{array}
$$

Any set of MFN tariffs $\left(\tau_{2}, \tau_{b}, \tau_{c}\right)$ satisfying (8) can be sustained as a self-enforcing multilateral trade agreement under our assumptions.

We first derive the lowest symmetric tariff satisfying (8). To this end we let $\tau \equiv \tau_{a}=\tau_{b}=\tau_{c}$ and note that (8) will be satisfied with equality at $\tau=\tau^{N}$. To explore the possibility that lower symmetric tariffs can be sustained, we note that, under (7), as $\tau$ is lowered from $\tau^{\mathrm{N}}$, country C's incentive constraint (ICC) in (8) will be the first to bind. We thus look for a tariff below $\tau^{\mathrm{N}}$ that makes ICC hold with equality: 


$$
\Omega(\tau)=\frac{\delta_{L}}{1-\delta_{L}} \hat{\omega}(\tau, \tau, \tau)
$$

Noting that $\hat{\omega}(\tau, \tau, \tau)=\beta\left[\left(\tau^{N}\right)^{2}-(\tau)^{2}\right] / 3$, we find that the lowest symmetric tariff, which we denote by $\underline{\tau}$, is given by

$$
\underline{\tau}=\left[\frac{4-7 \delta_{L}}{4-\delta_{L}}\right] \tau^{N}
$$

Hence, as (9) indicates, under condition (7) multilateral free trade can be supported if and only if $\delta_{L} \geq 4 / 7$. Henceforth we assume that $\delta_{L}<4 / 7$.

We next observe from (8) that countries A and B, being more patient than C, have "slack" in their respective incentive constraints at $\underline{\tau}$, i.e., ICA and ICB hold with strict inequality at $\underline{\tau}$, and thus $\mathrm{A}$ and $\mathrm{B}$ could sustain even lower MFN tariffs in a self-enforcing agreement. We therefore explore the "Hegemonic" role that could be played by countries $\mathrm{A}$ and $\mathrm{B}$ in a multilateral trading system by allowing them to liberalize further than $\underline{\tau}$ on an MFN basis. Having relaxed the restriction of overall symmetry, we maintain the restriction that $\mathrm{A}$ and $\mathrm{B}$ impose symmetric tariffs $\tau_{a}=\tau_{b}$ and now look for the set of MFN tariffs $\left(\tau_{a}, \tau_{a}, \tau_{c}\right)$ that lie below the Nash level and satisfy (8).

To this end, we denote by $\tau_{c}\left(\tau_{a}\right)$ the lowest MFN tariff sustainable by country $\mathrm{C}$ when facing a tariff $\tau_{a}$ from both its trading partners $A$ and $B$, and observe from (8) that $\tau_{c}\left(\tau_{a}\right)$ will be defined by the lower root of

$$
\Omega\left(\tau_{c}\right)=\frac{\delta_{L}}{1-\delta_{L}} \hat{\omega}\left(\tau_{c}, \tau_{a}, \tau_{a}\right)
$$

Solving (10) explicitly yields

$$
\tau_{C}\left(\tau_{\bar{a}}\right)=\tau^{N}-\frac{1}{2} \sqrt{\delta_{L}\left(7 \tau^{N}-\tau_{\bar{a}}\right)\left(\tau^{N}-\tau_{a}\right)} .
$$

We note that $\tau_{c}\left(\tau_{a}=\tau^{N}\right)=\tau^{N}, \tau_{c}\left(\tau_{a}=\underline{\tau}\right)=\tau, \quad \partial \tau_{c}\left(\tau_{a}=\tau^{N}\right) / \partial \tau_{a}=\infty$, and that $\tau_{c}\left(\tau_{a}\right)$ is increasing and convex over $\tau_{a} \in\left[0, \tau^{N}\right]$. Intuitively, country $C$ is unable to sustain a tariff below 
the Nash level when countries A and B select their Nash tariffs, since C would be treated no less favorably by A and B in a trade war. As countries A and B lower their import tariff, however, country $\mathrm{C}$ would now have something to lose in a trade war with $\mathrm{A}$ and $\mathrm{B}$, and so country $\mathrm{C}$ can sustain a tariff below the Nash level despite the consequent positive incentive to defect.

Similarly, we denote by $\tau_{a}\left(\tau_{c}\right)$ the lowest MFN tariff sustainable by country A when facing a symmetric tariff from country $B$ and a tariff $\tau_{c}$ from country $C$. We note from $(8)$ that $\tau_{a}\left(\tau_{c}\right)$ will be defined by the lower root of

$$
\Omega\left(\tau_{a}\right)=\frac{\delta_{H}}{1-\delta_{H}} \hat{\omega}\left(\tau_{a}, \tau_{a}, \tau_{c}\right) .
$$

Solving (11) explicitly yields

$$
\tau_{a}\left(\tau_{c}\right)=\frac{3\left[2-\delta_{H}\right]-\sqrt{\left(\frac{9}{4} \delta_{H}\right)^{2}-4 \beta\left(8-\delta_{H}\right) \delta_{H}\left(\tau_{c}-\tau^{N}\right)\left[\frac{9}{4}-\beta\left(\tau_{c}-\tau^{N}\right)\right]}}{2 \beta\left(8-\delta_{H}\right)}
$$

We observe that $\tau_{a}\left(\tau_{c}=\tau^{N}\right)<\tau^{N}, \tau_{a}\left(\tau_{c}=\underline{\tau}\right)<\underline{\tau}$, and that $\tau_{a}\left(\tau_{c}\right)$ is increasing and convex over $\tau_{C} \in\left[0, \tau^{N}\right]$. It is interesting to observe that country A can sustain a tariff below $\tau^{N}$ even when $\tau_{C}=\tau^{N}$. Intuitively, cooperation between countries $A$ and $B$ is valuable even when $C$ sets tariffs non-cooperatively, and under MFN countries A and B can cooperate with one another only if they extend their low tariffs to exports from country $\mathrm{C}$ as well. The fact that a tariff below $\underline{\tau}$ can be sustained by $\mathrm{A}$ and $\mathrm{B}$ even if they face the tariff $\underline{\tau}$ from country $\mathrm{C}$ reflects the relative patience of $A$ and $B$ as compared to $C$. Finally, the positive slope exhibited by $\tau_{a}\left(\tau_{c}\right)$ reflects familiar reasoning: When country $\mathrm{C}$ cooperates with a lower import tariff, countries $\mathrm{A}$ and $\mathrm{B}$ recognize a higher cost to a trade war and are therefore able to sustain lower tariffs.

The properties of $\tau_{c}\left(\tau_{a}\right)$ and $\tau_{a}\left(\tau_{c}\right)$ imply that there are two cases to consider, depending on the value of $\delta_{H}$. These two cases are distinguished by whether or not countries A and $\mathrm{B}$ can sustain free trade policies in a self-enforcing agreement ( $\mathrm{C}$ can not given our assumption that $\left.\delta_{L}<4 / 7\right)$. In particular, it can be shown that there exists a function $\delta_{H}=\delta_{H}\left(\delta_{L}\right)$ with $\delta_{H}(0)=8 / 7>\delta_{H}(4 / 7)=4 / 7$ and $\partial \delta_{H} / \partial \delta_{L}<0$ such that $\left(\tau_{a}=0, \tau_{b}=0, \tau_{C}=\tau_{C}(0)\right)$ is 
sustainable as a self-enforcing agreement if and only if $\delta_{H} \geq \delta_{H}\left(\delta_{L}\right)$. Figures $2 \mathrm{a}$ and $2 \mathrm{~b}$ illustrate.

Figure 2a illustrates case 1 , in which $\delta_{H} \in\left[\delta_{L}, \delta_{H}\left(\delta_{L}\right)\right)$. Here, the point labeled $\mathrm{H}$ depicts the "Hegemonic" equilibrium in which A and B reduce their MFN tariffs below the symmetric most-cooperative level $\underline{\tau}$. The hegemonic liberalization of $\mathrm{A}$ and $\mathrm{B}$ enhances the value of the agreement to $\mathrm{C}$, thereby increasing the cost of a trade war, and allowing $\mathrm{C}$ to undertake further liberalization as well. Note, however, that the "multiplier" effect associated with the MFN liberalization of $\mathrm{A}$ and $\mathrm{B}$ can not induce $\mathrm{C}$ to fully reciprocate with equal liberalization of its own, and so A and B act as 'hegemons," allowing $\mathrm{C}$ to "free ride" to some extent on their MFN liberalization. The point $\mathrm{H}$ reflects the most-cooperative MFN tariff combination sustainable, that is, the combination of MFN tariffs that maximizes the joint welfare of $A, B$, and $\mathrm{C}$ subject to their incentive constraints. ${ }^{5}$ In case 1 illustrated in Figure 2a, point $\mathrm{H}$ entails binding incentive constraints for all countries and all tariffs are strictly positive.

Figure $2 \mathrm{~b}$ illustrates case 2 , in which $\delta_{H} \in\left[\delta_{H}\left(\delta_{L}\right), 1\right)$. Here, the point labeled $\mathrm{H}$ again depicts the Hegemonic equilibrium in which $\mathrm{A}$ and $\mathrm{B}$ reduce their MFN tariffs below the symmetric most-cooperative level $\tau$. As in case 1, the hegemonic liberalization of A and B enhances the value of the agreement to $\mathrm{C}$, thereby increasing the cost of a trade war, and allowing $\mathrm{C}$ to undertake further liberalization as well. And again, as in case 1, the point $\mathrm{H}$ reflects the most-cooperative MFN tariff combination sustainable. However, in case 2 illustrated in Figure $2 b$, point $\mathrm{H}$ entails free trade for countries $\mathrm{A}$ and $\mathrm{B}$, with a binding incentive constraint only for country $\mathrm{C}$ whose tariff is strictly positive.

In the next sub-sections we assume $\delta_{H} \in\left[\delta_{L}, \delta_{H}\left(\delta_{L}\right)\right)$, so that $\mathrm{A}$ and $\mathrm{B}$ can not achieve free trade policies on an MFN basis, and ask how preferential agreements between them can affect the degree of multilateral tariff cooperation.

\section{III.B Free Trade Agreements}

We first suppose that countries A and B negotiate a free trade agreement. We abstract

${ }^{5}$ It is straightforward to demonstrate that combinations of $\tau_{a}=\tau_{b}$ and $\tau_{c}$ along which $\hat{W}^{A}+\hat{W}^{B}+\hat{W}^{C}$ is held constant are represented over the positive-tariff quadrant as negatively-sloped curves, with joint welfare being higher on curves that are closer to the origin. Looking to Figures $2 a$ and $2 b$, it is then straightforward to see that point $H$ maximizes joint welfare. (Note that $\tau_{a}\left(\tau_{c}\right)$ is concave in these figures, since $\tau_{c}$ is on the $y$ axis.) 
from enforcement issues associated with the free trade agreement itself, and simply assume that it can be enforced. Moreover, we take the existence of the free trade agreement between A and $B$ to be immutable: That is, we assume that it would not break down in the event of a breakdown in the multilateral agreement. The ability of A and B to enforce their free trade agreement when multilateral free trade can not be enforced might be thought of as reflecting the high discount factors shared by these two countries. Alternatively, cultural or political links between A and B might facilitate more explicit enforcement mechanisms than are possible in a multilateral agreement. In any event, our focus is on the impact of the free trade agreement between $\mathrm{A}$ and $\mathrm{B}$ on the most-cooperative tariffs sustainable in the multilateral agreement.

The free trade agreement between $A$ and $B$ implies that $\tau_{a}^{B}=\tau_{b}^{A} \equiv 0$. The symmetry between A and B implies that they will impose a symmetric multilateral tariff on imports from their external trading partner (C), which we denote by $\tau^{m} \equiv \tau_{a}^{C}=\tau_{b}^{C}$. Under a reversion to the Nash equilibrium, the free trade agreement between $\mathrm{A}$ and $\mathrm{B}$ remains in tact, and so the Nash punishment tariffs (and the best-defect tariffs) for A and B individually are given by (6) as $\tau^{m}=\tilde{\tau}_{a}^{C}\left(\tau_{a}^{B}=0\right)=3 / 22 \beta \equiv \tilde{\tau}<\tau^{N}$. Hence, the free trade agreement between A and B will reduce the effectiveness with which these countries can punish $\mathrm{C}$ in the event $\mathrm{C}$ were to defect from the multilateral agreement. Finally, country $\mathrm{C}$ will continue to abide by the principle of MFN under the multilateral agreement, and so we let $\tau_{c} \equiv \tau_{c}^{A}=\tau_{c}^{B}$. Under a reversion to the Nash equilibrium (or under a defection), country C's best-response tariff continues to be $\tau^{N}$.

To derive the impact of the free trade agreement between A and B on the most-cooperative multilateral tariffs sustainable under the multilateral agreement, we need to derive the new incentive constraints faced by each country as it sets its multilateral tariff policy. Now the onetime payoff in defecting from the multilateral agreement for each country is given by:

$$
\begin{aligned}
& \Omega^{A}\left(\tau^{m}, \tau_{c}\right) \equiv W^{A}\left(0, \tilde{\tau} ; 0, \tau^{m} ; \tau_{C}, \tau_{c}\right)-W^{A}\left(0, \tau^{m} ; 0, \tau^{m} ; \tau_{C}, \tau_{c}\right)=11 \frac{\beta}{18}\left(\tau-\tau^{m}\right)^{2} ; \\
& \Omega^{B}\left(\tau^{m}, \tau_{c}\right) \equiv W^{B}\left(\tilde{\tau}, 0 ; \tau_{C}, \tau_{c} ; 0, \tau^{m}\right)-W^{B}\left(\tau^{m}, 0 ; \tau_{C}, \tau_{c} ; 0, \tau^{m}\right)=11 \frac{\beta}{18}\left(\tilde{\tau}-\tau^{m}\right)^{2} ; \\
& \Omega^{C}\left(\tau^{m}, \tau_{c}\right) \equiv W^{C}\left(\tau^{N}, \tau^{N} ; \tau^{m}, 0 ; \tau^{m}, 0\right)-W^{C}\left(\tau_{c}, \tau_{c} ; \tau^{m}, 0 ; \tau^{m}, 0\right)=4 \frac{\beta}{9}\left(\tau_{c}-\tau^{N}\right)^{2} .
\end{aligned}
$$


The per-period cost of a trade war that would follow a defection is now given by:

$$
\begin{aligned}
\tilde{\omega}^{A}\left(\tau^{m}, \tau_{c}\right) & \equiv W^{A}\left(0, \tau^{m} ; 0, \tau^{m} ; \tau_{c}, \tau_{c}\right)-W^{A}\left(0, \tilde{\tau} ; 0, \tilde{\tau} ; \tau^{N}, \tau^{N}\right) \\
& =\frac{2\left(\tau^{m}-\tilde{\tau}\right)-\left(\tau_{c}-\tau^{N}\right)}{6}+\frac{\beta}{18}\left[\left(\tau_{c}\right)^{2}-\left(\tau^{N}\right)^{2}\right]-5 \frac{\beta}{9}\left[\left(\tau^{m}\right)^{2}-(\tilde{\tau})^{2}\right] ; \\
\tilde{\omega}^{B}\left(\tau^{m}, \tau_{c}\right) & \equiv W^{B}\left(\tau^{m}, 0 ; \tau_{C}, \tau_{c} ; 0, \tau^{m}\right)-W^{B}\left(\tilde{\tau}, 0 ; \tau^{N}, \tau^{N} ; 0, \tilde{\tau}\right) \\
& =\frac{2\left(\tau^{m}-\tilde{\tau}\right)-\left(\tau_{c}-\tau^{N}\right)}{6}+\frac{\beta}{18}\left[\left(\tau_{c}\right)^{2}-\left(\tau^{N}\right)^{2}\right]-5 \frac{\beta}{9}\left[\left(\tau^{m}\right)^{2}-(\tilde{\tau})^{2}\right] \\
\tilde{\omega}^{C}\left(\tau^{M}, \tau_{C}\right) & \equiv W^{C}\left(\tau_{C}, \tau_{C} ; \tau^{m}, 0 ; \tau^{m}, 0\right)-W^{C}\left(\tau^{N}, \tau^{N} ; \tilde{\tau}, 0 ; \tau, 0\right) \\
& =\frac{\left\langle\tau_{c}-\tau^{N}\right)-2\left(\tau^{m}-\tilde{\tau}\right)}{3}+4 \frac{\beta}{9}\left[\left(\tau^{m}\right)^{2}-(\tilde{\tau})^{2}\right]-4 \frac{\beta}{9}\left[\left(\tau_{c}\right)^{2}-\left(\tau^{N}\right)^{2}\right] .
\end{aligned}
$$

We can now present the incentive constraints that must be satisfied for any set of selfenforcing multilateral tariffs $\left(\tau^{m}, \tau_{c}\right)$ given the presence of a free trade agreement between $\mathrm{A}$ and $\mathrm{B}$. As before, the one-time benefit in deviating from the multilateral agreement must be no greater than the discounted cost to that country of the ensuing trade war. Formally, we have:

$$
\begin{array}{ll}
\text { ICA : } & \Omega^{A}\left(\tau^{m}, \tau_{C}\right) \leq \frac{\delta_{H}}{1-\delta_{H}} \tilde{\omega}^{A}\left(\tau^{m}, \tau_{C}\right) \\
I C B: & \Omega^{B}\left(\tau^{m}, \tau_{C}\right) \leq \frac{\delta_{H}}{1-\delta_{H}} \tilde{\omega}^{B}\left(\tau^{m}, \tau_{C}\right) \\
\text { ICC: } & \Omega^{C}\left(\tau^{m}, \tau_{C}\right) \leq \frac{\delta_{L}}{1-\delta_{L}} \tilde{\omega}^{C}\left(\tau^{m}, \tau_{C}\right) .
\end{array}
$$

Any set of tariffs $\left(\tau^{m}, \tau_{c}\right)$ satisfying (12) can be sustained as a self-enforcing multilateral trade agreement in the presence of a free trade agreement between $\mathrm{A}$ and $\mathrm{B}$.

In analogy with the approach taken above, we denote by $\tilde{\tau}_{C}\left(\tau^{m}\right)$ the lowest MFN tariff sustainable by country $C$ when facing a multilateral tariff $\tau^{m}$ from each of the free-tradeagreement partners A and B. From (12), $\tilde{\tau}_{C}\left(\tau^{m}\right)$ will be defined by the lower root of

$$
\Omega^{C}\left(\tau^{m}, \tau_{C}\right)=\frac{\delta_{L}}{1-\delta_{L}} \tilde{\omega}^{c}\left(\tau^{m}, \tau_{C}\right) .
$$


Solving (13) explicitly yields

$$
\tilde{\tau}_{C}\left(\tau^{m}\right)=\tau^{N}-\sqrt{\left(\tau^{m}-\tilde{\tau}\right) \delta_{L}\left(\tau^{m}-15 / 11 \beta\right)} \text {. }
$$

We note that $\tilde{\tau}_{C}\left(\tau^{m}=\tilde{\tau}\right)=\tau^{N}, \quad \partial \tilde{\tau}_{c}\left(\tau^{m}=\tilde{\tau}\right) / \partial \tau^{m}=\infty$, and that $\tilde{\tau}_{C}\left(\tau^{m}\right)$ is increasing and convex over $\tau^{m} \in[0, \tilde{\tau}]$.

In fact, it can be shown that $\tilde{\tau}_{c}\left(\tau^{m}\right)$ lies everywhere above the analogous function derived under MFN, $\tau_{c}\left(\tau_{a}=\tau^{m}\right)$, over the range $\tau^{m} \in[0, \tilde{\tau}]$. This reflects the punishment effect of a free trade agreement between $\mathrm{A}$ and $\mathrm{B}$, in that the free trade agreement has made these countries less-effective punishers of $\mathrm{C}$. Therefore $\mathrm{C}$ is less-effectively deterred from a defection by the threat of an ensuing trade war with $\mathrm{A}$ and $\mathrm{B} .{ }^{6}$ As a consequence of the punishment effect, it therefore follows that, facing a given multilateral tariff from countries $\mathrm{A}$ and $\mathrm{B}$ in the range $\tau^{m} \epsilon[0, \tilde{\tau}]$, incentive compatibility requires country $\mathrm{C}$ to raise its tariff if a free trade agreement between $\mathrm{A}$ and $\mathrm{B}$ is formed. Note also that the importance of this effect rises with $\delta_{L}$, country C's discount factor, and vanishes when $\delta_{L}=0$, as then $\tilde{\tau}_{C}\left(\tau^{m}\right) \equiv \tau_{C}\left(\tau_{a}=\tau^{m}\right) \equiv \tau^{N}$.

Similarly, exploiting the symmetry between $A$ and $B$, we denote by $\tau^{m}\left(\tau_{c}\right)$ the lowest multilateral tariff sustainable by countries A and B given their free trade agreement and facing an MFN tariff $\tau_{c}$ from country C. From (12), $\tilde{\tau}^{m}\left(\tau_{C}\right)$ will be defined by the lower root of

$$
\Omega^{A}\left(\tau^{m}, \tau_{C}\right)=\frac{\delta_{H}}{1-\delta_{H}} \widetilde{\omega}^{A}\left(\tau^{m}, \tau_{C}\right)
$$

Solving (14) explicitly yields

$$
\tilde{\tau}^{m}\left(\tau_{c}\right)=\frac{3\left(1+\delta_{H}\right)}{2 \beta\left(11-\delta_{H}\right)}-\frac{\sqrt{\left(36 \delta_{H} / 11\right)^{2}-4 \beta\left(11-\delta_{H}\right) \delta_{H}\left(\tau_{c}-\tau^{N}\right)\left[9 / 4-\beta\left(\tau_{c}-\tau^{N}\right)\right]}}{2 \beta\left(11-\delta_{H}\right)} .
$$

We note that $\tilde{\tau}^{m}\left(\tau_{c}=\tau^{N}\right)=\tilde{\tau}$, and that $\tilde{\tau}^{m}\left(\tau_{c}\right)$ is increasing and convex over $\tau_{c} \in\left[0, \tau^{N}\right]$.

There are two important new features of $\tilde{\tau}^{m}\left(\tau_{c}\right)$. First, contrary to the analogous

\footnotetext{
${ }^{6}$ At the same time, the free trade agreement between A and B has no impact on their export supplies to C, who therefore faces a one-time payoff from defection which is unchanged by the free trade agreement.
} 
function derived under MFN, $\tau_{a}\left(\tau_{c}\right)$, multilateral cooperation from A and $B\left(\tau^{m}<\tilde{\tau}\right)$ can not be sustained without cooperation from $\mathrm{C}\left(\tau_{c}<\tau^{N}\right)$. This reflects the fact that, with an exception from MFN granted and their free trade agreement in place, A and B no longer need to cooperate multilaterally in order to cooperate bilaterally. We will refer to this as the tariff discrimination effect of a preferential agreement, since the ability to negotiate bilateral tariff preferences allows countries to discriminate in their external tariffs against outside countries. This effect by itself will cause a free trade agreement between $A$ and $B$ to raise the lowest cooperative multilateral tariffs that $\mathrm{A}$ and $\mathrm{B}$ can sustain facing a given tariff from $\mathrm{C}$ in the multilateral agreement. Note also that the importance of this effect rises with $\delta_{H}$, the discount factor for countries A and B. But a second new feature of $\tilde{\tau}^{m}\left(\tau_{c}\right)$ arises as a result of the tariff complementarity effect, and reflects the fact that the free trade agreement between $\mathrm{A}$ and $\mathrm{B}$ makes these countries less enthusiastic about a high external tariff even in the absence of multilateral cooperation. This effect by itself will cause a free trade agreement between $\mathrm{A}$ and $\mathrm{B}$ to reduce the lowest cooperative multilateral tariffs that $\mathrm{A}$ and $\mathrm{B}$ can sustain for a given tariff from $\mathrm{C}$ in the multilateral agreement. Note that the importance of this effect is independent of the size of the discount factors. As a consequence, whether or not the free trade agreement between A and B enhances or interferes with the ability of these countries to sustain low multilateral tariffs against imports from $\mathrm{C}$ for a given multilateral tariff choice of $\mathrm{C}$ will depend on the relative strengths of these two effects, which depends in turn on the size of $\delta_{H}$.

The general features of $\tilde{\tau}_{c}\left(\tau^{m}\right)$ and $\tilde{\tau}^{m}\left(\tau_{c}\right)$ are illustrated in Figure 3 for the case where A and B can not sustain multilateral free trade. ${ }^{7}$ The point labeled FTA in Figure 3 reflects the set of most-cooperative multilateral tariffs sustainable in the presence of a free trade agreement between $\mathrm{A}$ and $\mathrm{B}$. These are the multilateral tariffs that maximize joint welfare of countries A,

\footnotetext{
${ }^{7}$ As in the case of MFN tariffs, a function $\delta_{H}\left(\delta_{L}\right)$ analogous to $\delta_{H}\left(\delta_{L}\right)$ can be defined such that $\left(\tau^{m}=0, \tau_{c}=\tilde{\tau}_{c}(0)\right)$ is sustainable as a self-enforcing multilateral agreement in the presence of a free trade agreement between $\mathrm{A}$ and $\mathrm{B}$ if and only if $\delta_{H} \geq \delta_{H}\left(\delta_{L}\right)$. We focus our discussion on the case where $\delta_{H}<\delta_{H}\left(\delta_{L}\right)$.
} 
$\mathrm{B}$, and $\mathrm{C}$ subject to their multilateral incentive constraints as contained in (12). ${ }^{8}$

As noted above, no general conclusion can be drawn about the impact of the free trade agreement between A and B on the most-cooperative multilateral tariff levels. However, we can illustrate the possibilities in a useful special case. In particular, consider the case in which $\delta_{L}=0$. As noted above, in this case, the punishment effect on C's ability to cooperate multilaterally is eliminated, leaving only two opposing effects of the free trade agreement on the ability of countries $\mathrm{A}$ and $\mathrm{B}$ to cooperate multilaterally with $\mathrm{C}$ : A tariff discrimination effect that tends to make free trade agreements bad for multilateral tariff cooperation and is stronger the higher is $\delta_{H}$, and a tariff complementarity effect that tends to make free trade agreements good for multilateral tariff cooperation and whose strength is independent of $\delta_{H}$. In this case, there exists a critical value of $\delta_{H}=56 / 73 \equiv \delta$ such that free trade agreements are bad for multilateral tariff cooperation if and only if $\delta_{H} \in(\delta, 1)$.

Figure 4 illustrates by depicting the most-cooperative multilateral tariffs under MFN (labeled MFN) and in the presence of a free trade agreement between A and B (labeled FTA) in the case where $\delta_{L}=0$ and $\delta_{H} \epsilon(\delta, 1)$. As depicted, with $\delta_{L}=0, C$ must set its non-cooperative tariff $\tau^{N}$ regardless of the presence or absence of a free trade agreement between $\mathrm{A}$ and $\mathrm{B}$. Under MFN, countries A and B must offer the same liberalization to C that they achieve reciprocally, and the most-cooperative MFN tariffs are depicted at point D. Countries A and B can sustain MFN tariffs below the Nash level even though country $\mathrm{C}$ offers nothing in return because A's liberalization is valuable to $\mathrm{B}$ and vice versa. Under a free trade agreement between $\mathrm{A}$ and $\mathrm{B}$, however, these countries achieve the gains from cooperation bilaterally, and are therefore unwilling to liberalize their multilateral tariffs if their multilateral trading partners are unwilling to reciprocate. This is the tariff discrimination effect of the free trade agreement, and it removes the ability to liberalize multilaterally away from the Nash point to point D. On the other hand, the tariff complementarity effect of the free trade agreement reduces the level of the multilateral tariffs desired by $\mathrm{A}$ and $\mathrm{B}$ in a Nash equilibrium, moving the Nash point from $\mathrm{N}$ in Figure 4 to

\footnotetext{
${ }^{8}$ In analogy with footnote 5 for the MFN game, one can show that the iso-joint-welfare contour takes a negative slope through the positive-tariff quadrant, and this implies that the point labeled FTA in Figure 3 represents the mostcooperative tariffs for the free-trade-area game.
} 
the point labeled $\tilde{N}$. For $\delta_{H} \epsilon(\delta, 1)$, the tariff discrimination effect dominates the tariff complementarity effect and, as illustrated in Figure 4, the most-cooperative multilateral tariffs rise with the arrival of the free trade agreement between A and B.

\section{III.C Customs Unions}

We next suppose that countries $A$ and $B$ form a customs union. As with the free trade agreement analyzed above, we abstract from enforcement issues associated with the customs union itself and simply assume that it can be enforced and is immutable. We consider the impact of this customs union on the most-cooperative tariffs sustainable in the multilateral agreement.

As with the free trade agreement, the customs union between $\mathrm{A}$ and $\mathrm{B}$ implies that $\tau_{a}^{B}=\tau_{b}^{A} \equiv 0$. And as before, the symmetry between $\mathrm{A}$ and $\mathrm{B}$ implies that they will impose a symmetric multilateral tariff on imports from their external trading partner (C), which we denote by $\tau^{m} \equiv \tau_{a}^{c}=\tau_{b}^{c}$. However, under a reversion to the Nash equilibrium, the customs union between $\mathrm{A}$ and $\mathrm{B}$ remains in tact, and so the Nash punishment tariffs (and the best-defect tariffs) for $\mathrm{A}$ and $\mathrm{B}$, which will be chosen to maximize their joint welfare, are given by $\tau^{m}=\bar{\tau}_{a}^{C}\left(\tau_{a}^{B}=0\right)=3 / 10 \beta \equiv \bar{\tau} \epsilon\left(\widetilde{\tau}, \tau^{N}\right)$. Hence, the customs union between $A$ and $B$ will reduce the effectiveness with which these countries can punish $\mathrm{C}$ with a high tariff, but the ability of $\mathrm{A}$ and $\mathrm{B}$ to punish $\mathrm{C}$ will not be diminished to the extent that it would be under a free trade agreement between these two countries. This is because members of a customs union are concerned about the negative externality imposed on other customs union members when they lower their external tariff and thereby reduce the tariff advantage offered to their customs union partners. This concern leads customs union members to desire higher external tariffs than members of a free trade agreement. Finally, as before, country $\mathrm{C}$ will continue to abide by the principle of MFN under the multilateral agreement, and so we continue to let $\tau_{c} \equiv \tau_{C}^{A}=\tau_{C}^{B}$. Under a reversion to the Nash equilibrium (or under a defection), country C's best-response tariff continues to be $\tau^{N}$.

To derive the impact of the customs union between $\mathrm{A}$ and $\mathrm{B}$ on the most-cooperative multilateral tariffs sustainable under the multilateral agreement, we again need to derive the new incentive constraints faced by each country as it sets its multilateral tariff policy. Since A and B now choose their trade policies to maximize joint welfare, we will have just two incentive 
constraints. In the presence of a customs union between $\mathrm{A}$ and $\mathrm{B}$, the one-time payoff in defecting from the multilateral agreement for $\mathrm{A}$ and $\mathrm{B}$ jointly (expressed per-country in A's notation) and for $\mathrm{C}$ is given, respectively, by:

$$
\begin{aligned}
& \bar{\Omega}^{A}\left(\tau^{m}, \tau_{c}\right) \equiv W^{A}\left(0, \bar{\tau} ; 0, \bar{\tau} ; \tau_{c}, \tau_{c}\right)-W^{A}\left(0, \tau^{m} ; 0, \tau^{m} ; \tau_{c}, \tau_{c}\right)=5 \frac{\beta}{9}\left(\bar{\tau}-\tau^{m}\right)^{2} ; \\
& \bar{\Omega}^{C}\left(\tau^{m}, \tau_{c}\right) \equiv W^{C}\left(\tau^{N}, \tau^{N} ; \tau^{m}, 0 ; \tau^{m}, 0\right)-W^{C}\left(\tau_{c}, \tau_{c} ; \tau^{m}, 0 ; \tau^{m}, 0\right)=4 \frac{\beta}{9}\left(\tau_{c}-\tau^{N}\right)^{2} .
\end{aligned}
$$

The corresponding per-period cost of a trade war that would follow a defection is now given by:

$$
\begin{aligned}
\bar{\omega}^{A}\left(\tau^{m}, \tau_{c}\right) & \equiv W^{A}\left(0, \tau^{m} ; 0, \tau^{m} ; \tau_{c}, \tau_{c}\right)-W^{A}\left(0, \bar{\tau} ; 0, \bar{\tau} ; \tau^{N}, \tau^{N}\right) \\
& =\frac{2\left(\tau^{m}-\bar{\tau}\right)-\left(\tau_{c}-\tau^{N}\right)}{6}+\frac{\beta}{18}\left[\left(\tau_{c}\right)^{2}-\left(\tau^{N}\right)^{2}\right]-5 \frac{\beta}{9}\left[\left(\tau^{m}\right)^{2}-(\bar{\tau})^{2}\right] ; \\
\bar{\omega}^{C}\left(\tau^{M}, \tau_{c}\right) & \equiv W^{C}\left(\tau_{c}, \tau_{c} ; \tau^{m}, 0 ; \tau^{m}, 0\right)-W^{C}\left(\tau^{N}, \tau^{N} ; \bar{\tau}, 0 ; \bar{\tau}, 0\right) \\
& =\frac{\left(\tau_{c}-\tau^{N}\right)-2\left(\tau^{m}-\bar{\tau}\right)}{3}+4 \frac{\beta}{9}\left[\left(\tau^{m}\right)^{2}-(\bar{\tau})^{2}\right]-4 \frac{\beta}{9}\left[\left(\tau_{c}\right)^{2}-\left(\tau^{N}\right)^{2}\right] .
\end{aligned}
$$

We can now present the incentive constraints that must be satisfied for any set of multilateral tariffs $\left(\tau^{m}, \tau_{c}\right)$ that are self-enforcing under the multilateral agreement given the presence of a customs union between A and B. As before, the one-time benefit in deviating from the multilateral agreement must be no greater than the discounted cost to that country of the ensuing trade war. Formally, we have:

$$
\begin{aligned}
\text { ICAB }: & \bar{\Omega}^{A}\left(\tau^{m}, \tau_{C}\right) \leq \frac{\delta_{H}}{1-\delta_{H}} \bar{\omega}^{A}\left(\tau^{m}, \tau_{C}\right) \\
\text { ICC }: & \bar{\Omega}^{C}\left(\tau^{m}, \tau_{C}\right) \leq \frac{\delta_{L}}{1-\delta_{L}} \bar{\omega}^{C}\left(\tau^{m}, \tau_{c}\right) .
\end{aligned}
$$

Any set of tariffs $\left(\tau^{m}, \tau_{c}\right)$ satisfying (15) can be sustained as a self-enforcing multilateral trade agreement in the presence of a customs union between $\mathrm{A}$ and $\mathrm{B}$.

In analogy with the approach taken in the previous subsections, we denote by $\bar{\tau}_{c}\left(\tau^{m}\right)$ the lowest MFN tariff sustainable by country $\mathrm{C}$ when facing a multilateral tariff $\tau^{m}$ from each of 
countries $\mathrm{A}$ and $\mathrm{B}$, who together maintain a customs union between them. From (15), $\bar{\tau}_{c}\left(\tau^{m}\right)$ will be defined by the lower root of

$$
\bar{\Omega}^{c}\left(\tau^{m}, \tau_{C}\right)=\frac{\delta_{L}}{1-\delta_{L}} \bar{\omega}^{c}\left(\tau^{m}, \tau_{C}\right)
$$

Solving (16) explicitly yields

$$
\bar{\tau}_{c}\left(\tau^{m}\right)=\tau^{N}-\sqrt{\left(\tau^{m}-\bar{\tau}\right) \delta_{L}\left(\tau^{m}-6 / 5 \beta\right)} .
$$

We note that $\bar{\tau}_{c}\left(\tau^{m}=\bar{\tau}\right)=\tau^{N}, \quad \partial \bar{\tau}_{c}\left(\tau^{m}=\bar{\tau}\right) / \partial \tau^{m}=\infty$, and that $\bar{\tau}_{c}\left(\tau^{m}\right)$ is increasing and convex over $\tau^{m} \in[0, \bar{\tau}]$.

Moreover, it can be shown that $\bar{\tau}_{C}\left(\tau^{m}\right)$ lies everywhere below the analogous function derived in the presence of a free trade agreement, $\tilde{\tau}_{c}\left(\tau^{m}\right)$, over the range $\tau^{m} \in[0, \tilde{\tau}]$. This reflects the fact that the punishment effect associated with a free trade agreement between $\mathrm{A}$ and $\mathrm{B}$ is more pronounced than that associated with a customs union between these two countries. Consequently, country $\mathrm{C}$ is less-effectively deterred from a defection by the threat of an ensuing trade war when A and B form a free trade agreement than when they form a customs union. It therefore follows that, facing a given multilateral tariff from countries $\mathrm{A}$ and $\mathrm{B}$ in the range $\tau^{m} \in[0, \tilde{\imath}]$, incentive compatibility requires country $C$ to raise its tariff by a greater amount if a free trade agreement between A and B is formed than if A and B instead form a customs union. Comparing $\bar{\tau}_{c}\left(\tau^{m}\right)$ to $\tau_{c}\left(\tau_{a}\right)$, the analogous function derived under the restriction of MFN, we note that $\bar{\tau}_{C}\left(\tau^{m}\right)$ lies above $\tau_{C}\left(\tau_{a}=\tau^{m}\right)$ for $\tau^{m}$ sufficiently close to $\bar{\tau}$ but below $\tau_{C}\left(\tau_{a}=\tau^{m}\right)$ for $\tau^{m}$ sufficiently close to zero. This reflects the fact that, for $\tau^{m}$ sufficiently close to zero, country $\mathrm{C}$ can be punished more severely by $\mathrm{A}$ and $\mathrm{B}$ when they join together in a customs union than when they select tariffs in a non-discriminatory fashion. Finally, note again that the importance of the punishment effect rises with $\delta_{L}$, the discount factor for country $\mathrm{C}$, and that in particular this effect vanishes when $\delta_{L}=0$, as then $\bar{\tau}_{c}\left(\tau^{m}\right) \equiv \tilde{\tau}_{C}\left(\tau^{m}\right) \equiv \tau_{C}\left(\tau_{a}=\tau^{m}\right) \equiv \tau^{N}$.

Similarly, exploiting the symmetry between $A$ and $B$, we denote by $\bar{\tau}^{m}\left(\tau_{c}\right)$ the lowest multilateral tariff sustainable by countries A and B given their customs union and facing an MFN 
tariff $\tau_{C}$ from country C. From $(15), \bar{\tau}^{m}\left(\tau_{C}\right)$ will be defined by the lower root of

$$
\bar{\Omega}^{A}\left(\tau^{m}, \tau_{C}\right)=\frac{\delta_{H}}{1-\delta_{H}} \bar{\omega}^{A}\left(\tau^{m}, \tau_{C}\right)
$$

Solving (17) explicitly yields

$$
\bar{\tau}^{m}\left(\tau_{c}\right)=\bar{\tau}-\sqrt{\frac{\left(\tau^{N}-\tau_{C}\right) \delta_{H}\left(\frac{21}{8} \beta-\tau_{c}\right)}{10}}
$$

We note that $\bar{\tau}^{m}\left(\tau_{c}=\tau^{N}\right)=\bar{\tau}$, and that $\bar{\tau}^{m}\left(\tau_{c}\right)$ is increasing and convex over $\tau_{c} \epsilon\left[0, \tau^{N}\right]$. As with $\tilde{\tau}^{m}\left(\tau_{c}\right)$, the relative strengths of two opposing effects -- the tariff discrimination effect (the strength of which increases in $\delta_{H}$ ) and the tariff complementarity effect (which is independent of $\left.\delta_{H}\right)$-- determine whether $\bar{\tau}^{m}\left(\tau_{c}\right)$ lies above or below $\tau_{a}\left(\tau_{c}\right)$ over the range $\tau_{c} \in\left[0, \tau^{N}\right]$, and therefore whether a customs union between $A$ and $B$ increases or reduces the lowest cooperative multilateral tariff that $\mathrm{A}$ and $\mathrm{B}$ can sustain for a given tariff from $\mathrm{C}$ in the multilateral agreement. However, as noted above, the tariff complementarity effect is weaker in the case of a customs union than in the case of a free trade agreement (hence $\bar{\tau}>\tilde{\tau}$ ), and thus the critical value of $\delta_{H}$ above which a customs union between $A$ and $B$ increases the lowest cooperative multilateral tariff that $\mathrm{A}$ and $\mathrm{B}$ can sustain for a given tariff from $\mathrm{C}$ in the multilateral agreement will tend to be lower than the analogous critical value in the presence of a free trade agreement.

The general features of $\bar{\tau}_{c}\left(\tau^{m}\right)$ and $\bar{\tau}^{m}\left(\tau_{c}\right)$ are illustrated in Figure 5 for the case where A and B can not sustain multilateral free trade. ${ }^{9}$ The point labeled CU in Figure 5 reflects the set of most-cooperative multilateral tariffs sustainable in the presence of a customs union between $\mathrm{A}$ and $\mathrm{B}$. These are the multilateral tariffs that maximize joint welfare of countries $\mathrm{A}, \mathrm{B}$, and $\mathrm{C}$ subject to their multilateral incentive constraints as contained in (15). ${ }^{10}$

\footnotetext{
${ }^{9} \mathrm{As}$ in the case of MFN tariffs, a function $\bar{\delta}_{H}\left(\delta_{L}\right)$ analogous to $\delta_{H}\left(\delta_{L}\right)$ can be defined such that $\left(\tau^{m}=0, \tau_{c}=\bar{\tau}_{C}(0)\right)$ is sustainable as a self-enforcing multilateral agreement in the presence of a customs union between $\mathrm{A}$ and $\mathrm{B}$ if and only if $\delta_{H} \geq \bar{\delta}_{H}\left(\delta_{L}\right)$. We focus our discussion on the case where $\delta_{H}<\bar{\delta}_{H}\left(\delta_{L}\right)$.

${ }^{10} \mathrm{Comments} \mathrm{characterizing} \mathrm{the} \mathrm{iso-joint-welfare} \mathrm{contours} \mathrm{analogous} \mathrm{to} \mathrm{those} \mathrm{in} \mathrm{footnote} 5$ apply.
} 
As with a free trade agreement, no general conclusion can be drawn about the impact of the customs union between $\mathrm{A}$ and $\mathrm{B}$ on the most-cooperative multilateral tariff levels. Again we illustrate the possibilities by turning to the useful special case where $\delta_{L}=0$. As noted above, in this case, the punishment effect on $\mathrm{C}^{\prime} \mathrm{s}$ ability to cooperate multilaterally is eliminated, leaving only two opposing effects of the customs union on the ability of countries A and B to cooperate multilaterally with C: A tariff discrimination effect, that tends to make customs unions bad for multilateral tariff cooperation and is stronger the higher is $\delta_{H}$, and a tariff complementarity effect that tends to make customs unions good for multilateral tariff cooperation and whose strength is independent of $\delta_{H}$ but, as noted above, weaker than the corresponding effect associated with a free trade agreement. Comparing the most-cooperative tariffs under MFN to those in the presence of a customs union between $\mathrm{A}$ and $\mathrm{B}$, we find that there exists a critical value of $\delta_{H}=8 / 31 \equiv \bar{\delta}$ such that customs unions are bad for multilateral tariff cooperation if and only if $\delta_{H} \in(\bar{\delta}, 1)$. Moreover, note that $\bar{\delta}<\delta$ : Hence, for the intermediate range of $\delta_{H} \in\langle\bar{\delta}, \delta]$, customs unions are bad for multilateral tariff cooperation while free trade agreements are good.

Figure 6 illustrates by depicting the most-cooperative multilateral tariffs under MFN (labeled MFN) and in the presence of a free trade agreement between A and B (labeled FTA) and in the presence of a customs union between $\mathrm{A}$ and $\mathrm{B}$ (labeled CU) in the case where $\delta_{L}=0$. Figure 6a depicts the case in which $\delta_{H} \in\left[\delta_{L}, \bar{\delta}\right)$, so that multilateral tariff cooperation under MFN is relatively ineffective. Here, the tariff complementarity effect outweighs the tariff discrimination effect for both free trade agreements and customs unions, and each form of preferential agreement allows a lower level of multilateral tariffs to be negotiated than would exist under MFN. Figure $6 \mathrm{~b}$ depicts the case where $\delta_{H} \epsilon(\bar{\delta}, \delta]$. Here, the tariff discrimination effect overwhelms the tariff complementarity effect for customs unions but is outweighed by the tariff complementarity effect for free trade agreements, so that free trade agreement continue to allow a lower level of multilateral tariffs but customs unions lead to a higher level of multilateral tariffs than would exist under MFN. Finally, Figure $6 \mathrm{c}$ depicts the case where $\delta_{H} \epsilon(\delta, 1)$. Here, the tariff discrimination effect overwhelms the tariff complementarity effect for both customs unions and free trade agreements, so that both forms of preferential agreement lead to a higher level of 
multilateral tariffs than would exist under MFN.

\section{Conclusion}

We have considered a three-country world in which each country's import market is served by competing exporters from its two trading partners. We have assumed that weak multilateral enforcement mechanisms prevent governments from implementing efficient trade policies through a multilateral agreement that requires tariffs to conform to the most-favored-nation (MFN) principle. We then ask whether exceptions from MFN for the purpose of forming preferential agreements can lead to a more efficient tariff structure under the multilateral agreement.

We identify three opposing effects of preferential agreements on the multilateral tariff structure in this setting. A first effect of a preferential agreement, the tariff complementarity effect, derives from the complementary relationship across the tariffs a country selects on imports from different trading partners: We find that reducing a tariff on imports from one source makes tariff reductions on imports from all other sources more attractive. This effect works to reduce the desired external tariffs of countries that join together in a preferential agreement, and we find that it is stronger under a free trade agreement than a customs union.

Two additional effects of preferential agreements arise only when enforcement issues are considered. One of these, the punishment effect, is the flip-side of the tariff complementarity effect. This effect serves to weaken the ability of the member countries of a preferential agreement to punish deviations from the multilateral agreement, thereby interfering with the ability of countries to sustain low tariffs under the multilateral agreement. As with the tariff complementarity effect, this effect is more pronounced under a free trade agreement than under a customs union. The other of these, the tariff discrimination effect, allows countries to discriminate against those who would "free ride" under MFN, and thus works to increase the desired external tariffs of countries that join together in a preferential agreement. The strength of this effect is independent of the form of the preferential agreement.

The relative strengths of these three effects determine the impact of a preferential agreement on the tariff structure under the multilateral agreement, and we find that preferential agreements can be either good or bad for multilateral tariff cooperation depending on parameters. In particular, we demonstrate that the three effects can be ranked when the non-member country 
is sufficiently impatient. In that event, the non-member country is focused on the present, and the punishment effect is eliminated. The tariff complementarity and discrimination effects remain, however, and the latter will dominate if and only if the two member countries are sufficiently patient. In this circumstance, the formation of a free-trade area leads to an overall deterioration in multilateral tariff cooperation. Furthermore, we find that customs union formation is more likely to harm multilateral tariff liberalization than is free-trade area formation, in the sense that the former leads to an increase in multilateral tariffs from member countries for a wider range of possible patience levels for the member countries.

Our results suggest a number of broader conclusions. First, it is important to keep in mind that since 1947 the formation of preferential agreements has occurred within the broader context of multilateral tariff cooperation under GATT (and now the WTO). Therefore, when assessing the impact of preferential agreements on external tariffs, it is critical that the analysis reflect the attempt to maintain multilateral tariff cooperation. The importance of this observation is manifested in our results above, where we find that the more ominous implications of preferential agreements for external tariffs arise only when attempts to maintain multilateral tariff cooperation and the associated enforcement difficulties are considered. Second, our results point to an intriguing possibility regarding the role of preferential agreements when the multilateral system is working poorly. The appeal of preferential agreements in such circumstances is sometimes viewed as signaling the demise of the multilateral system. Our results suggest that this conclusion is not necessarily warranted. Rather, our findings indicate that it is precisely when the multilateral system is working poorly (as when countries are sufficiently impatient) that preferential agreements can have their most desirable effects on the multilateral system. 


\section{References}

Bagwell, Kyle, and Robert W. Staiger, "Multilateral Tariff Cooperation During the Formation of Regional Free Trade Areas," International Economic Review, forthcoming, 1996a.

Bagwell, Kyle, and Robert W. Staiger, "Multilateral Tariff Cooperation During the Formation of Customs Unions," Journal of International Economics, forthcoming, 1996b.

Bagwell, Kyle, and Robert W. Staiger, "Reciprocal Trade Liberalization," NBER Working Paper No. 5488, March 1996c.

Bhagwati, Jagdish, The World Trading System at Risk, Princeton University Press, Princeton, Jew Jersey, 1991.

Bond, Eric, and Syropoulos, Costas, "Trading Blocs and the Sustainability of Inter-Regional Cooperation," mimeo, March 1993.

Bond, Eric, Syropoulos, Costas, and L. Alan Winters, "Deepening of Regional Integration and Multilateral Trade Agreements," mimeo, November 1995.

Dam, Kenneth, The GATT: Law and International Economic Organization, Chicago: University of Chicago Press, 1970.

Kindleberger, Charles P., "Dominance and Leadership in the International Economy: Exploitation, Public Goods, and Free Rides," International Studies Quarterly 25, No. 2, June 1981, pp. 242-254.

Richardson, Martin, "On Equilibrium in a Free Trade Area with Internal Trade," mimeo, April 1992.

Richardson, Martin, "Endogenous Protection and Trade Diversion," Journal of International Economics 34, 1993, 309-324. 


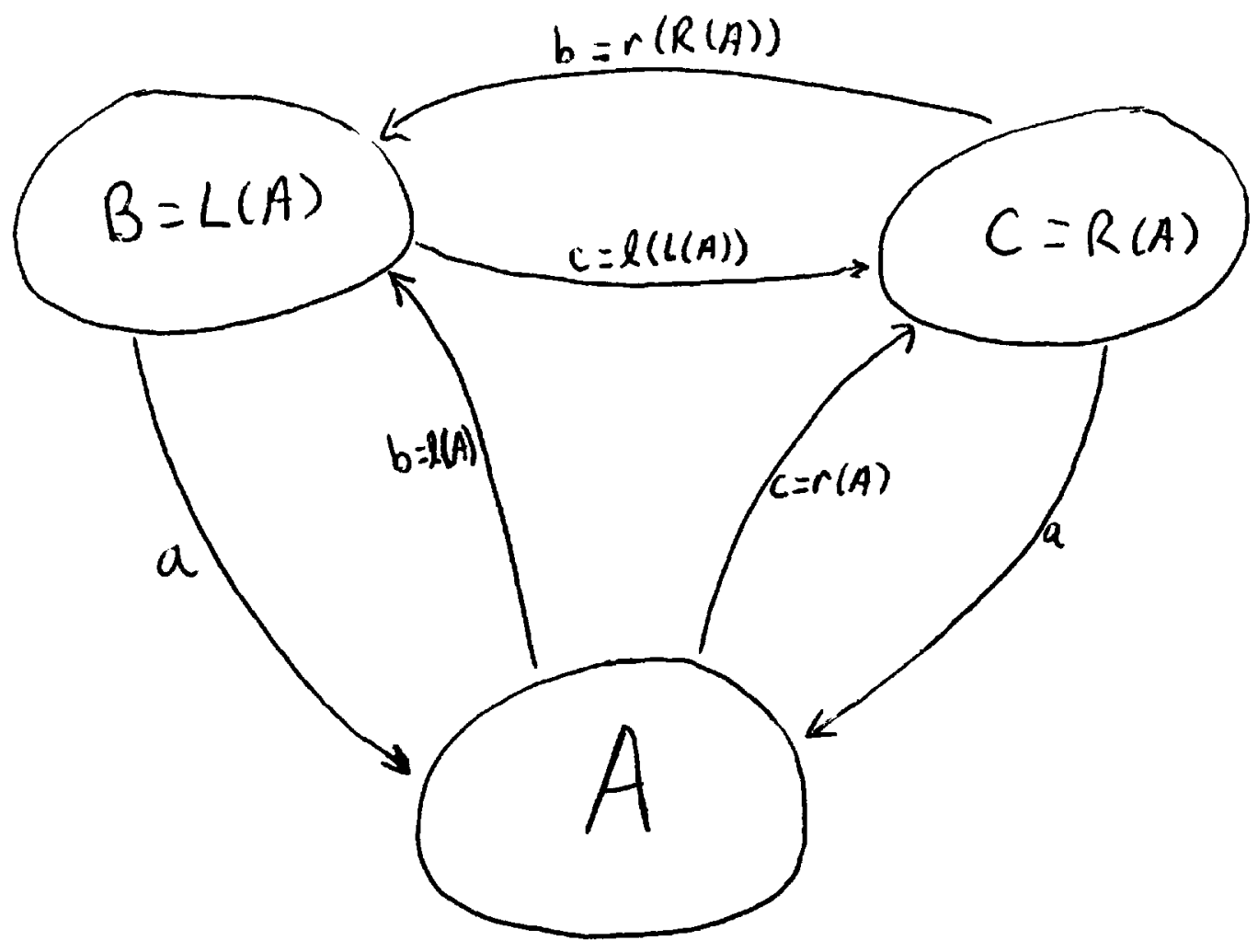

Figure 1 

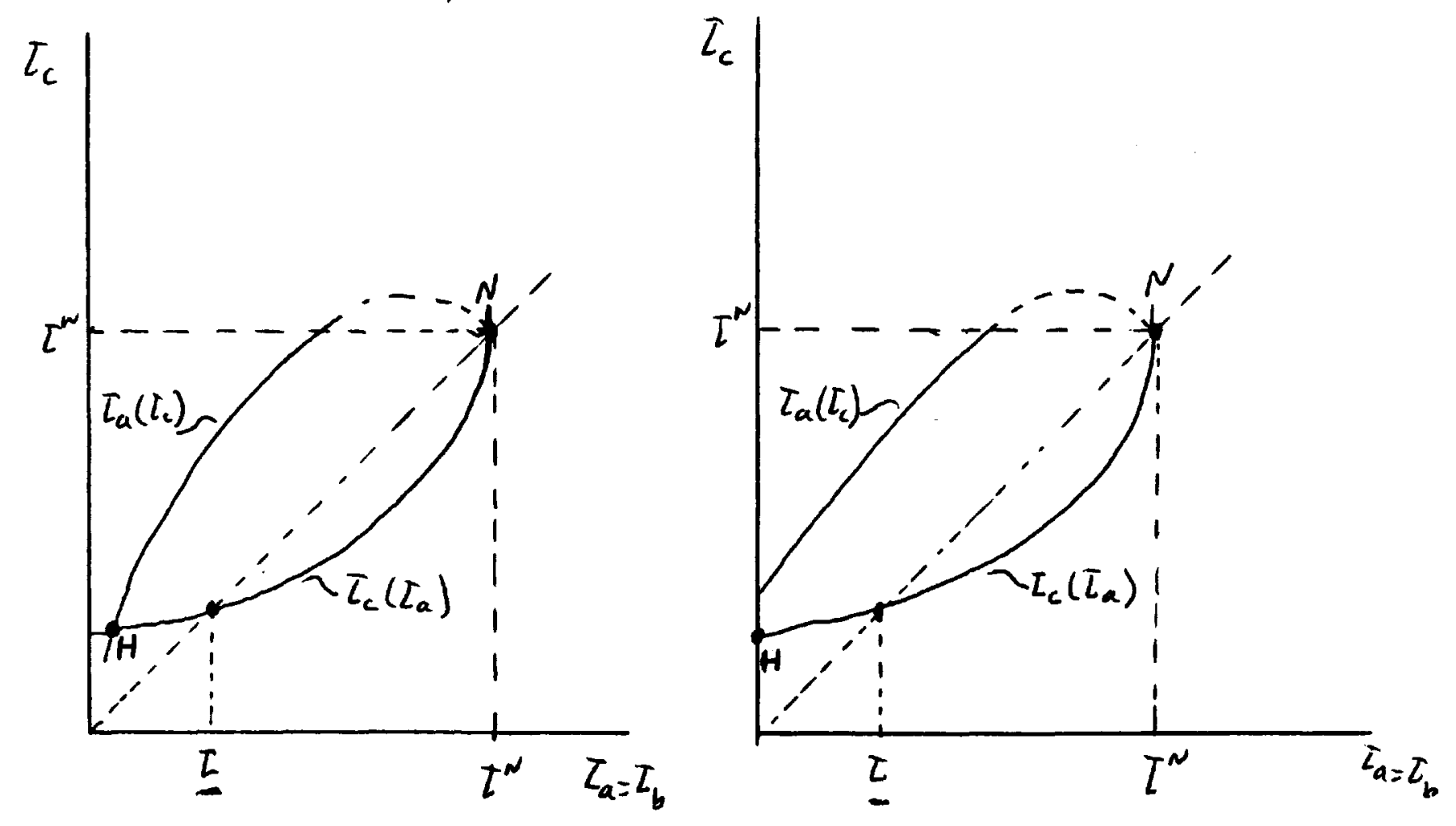

Figure 2 a

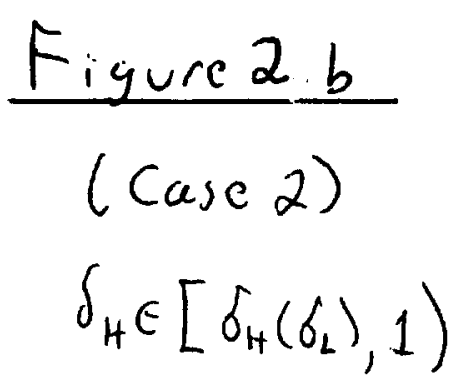

(case 1)

$\delta_{H} \in\left[\delta_{L}, \delta_{H}\left(\delta_{L}\right)\right)$

$\delta_{H} \in\left[\delta_{H}\left(\sigma_{L}\right), 1\right)$

Fisure 2 


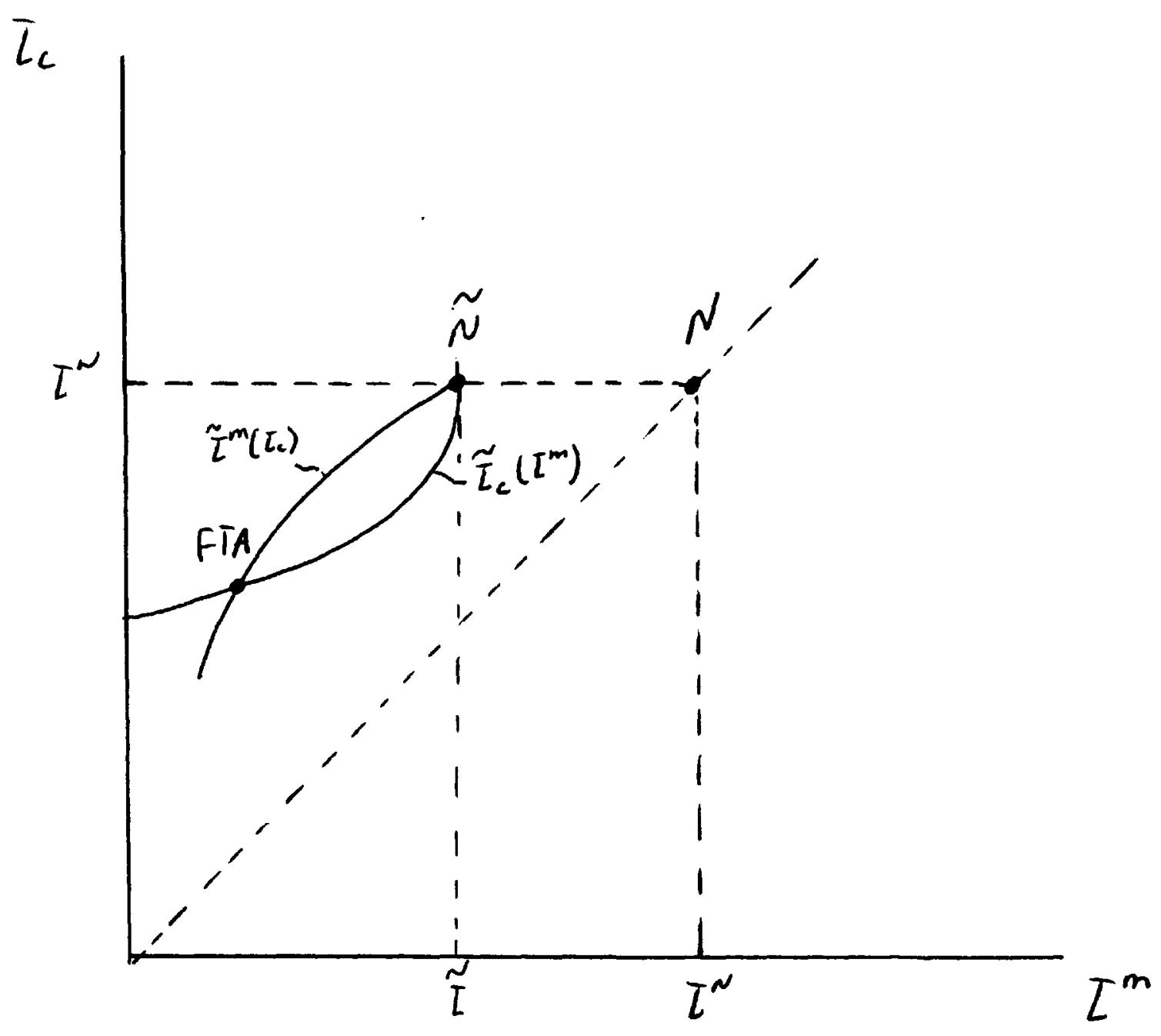

Figure 3 


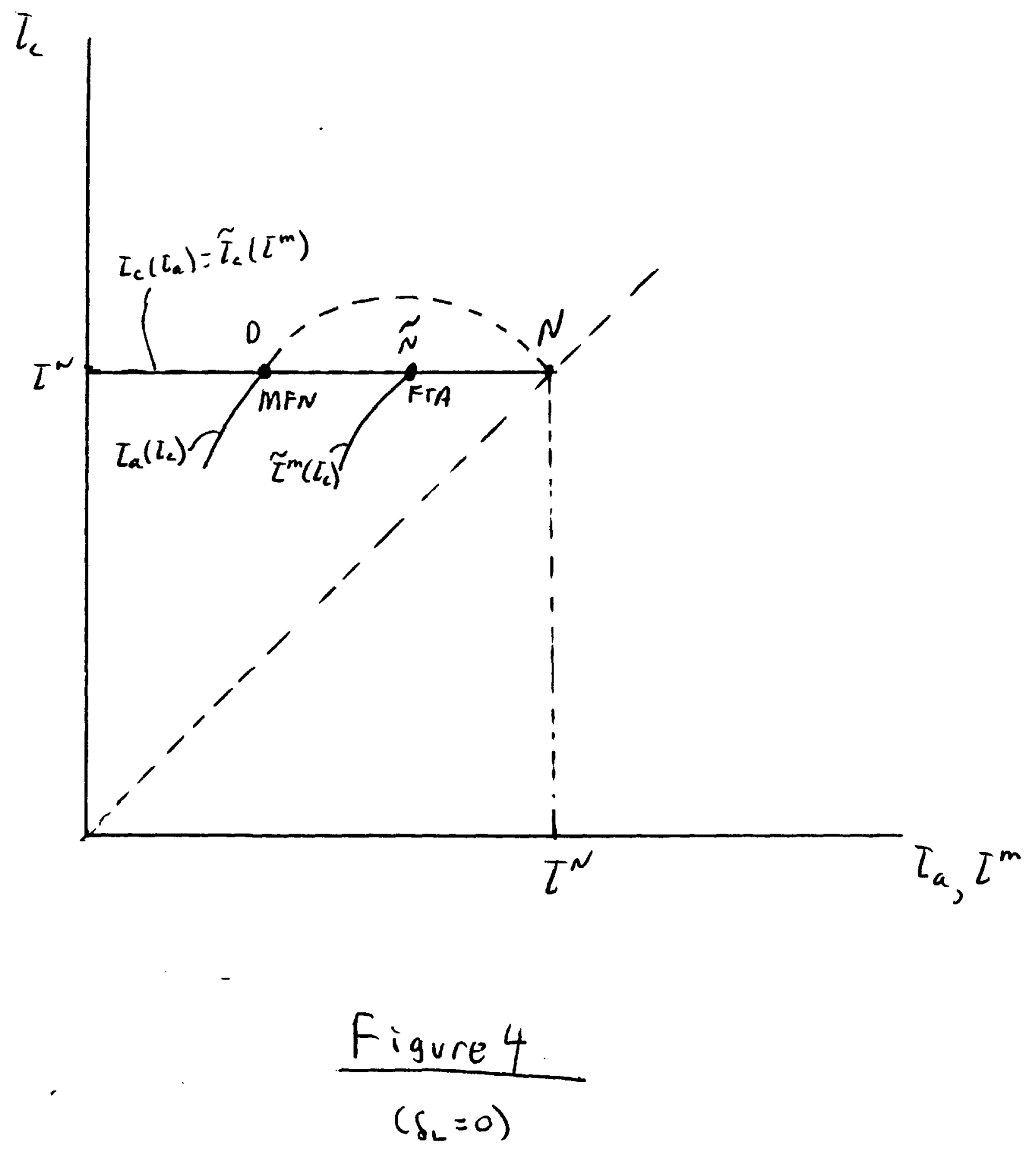




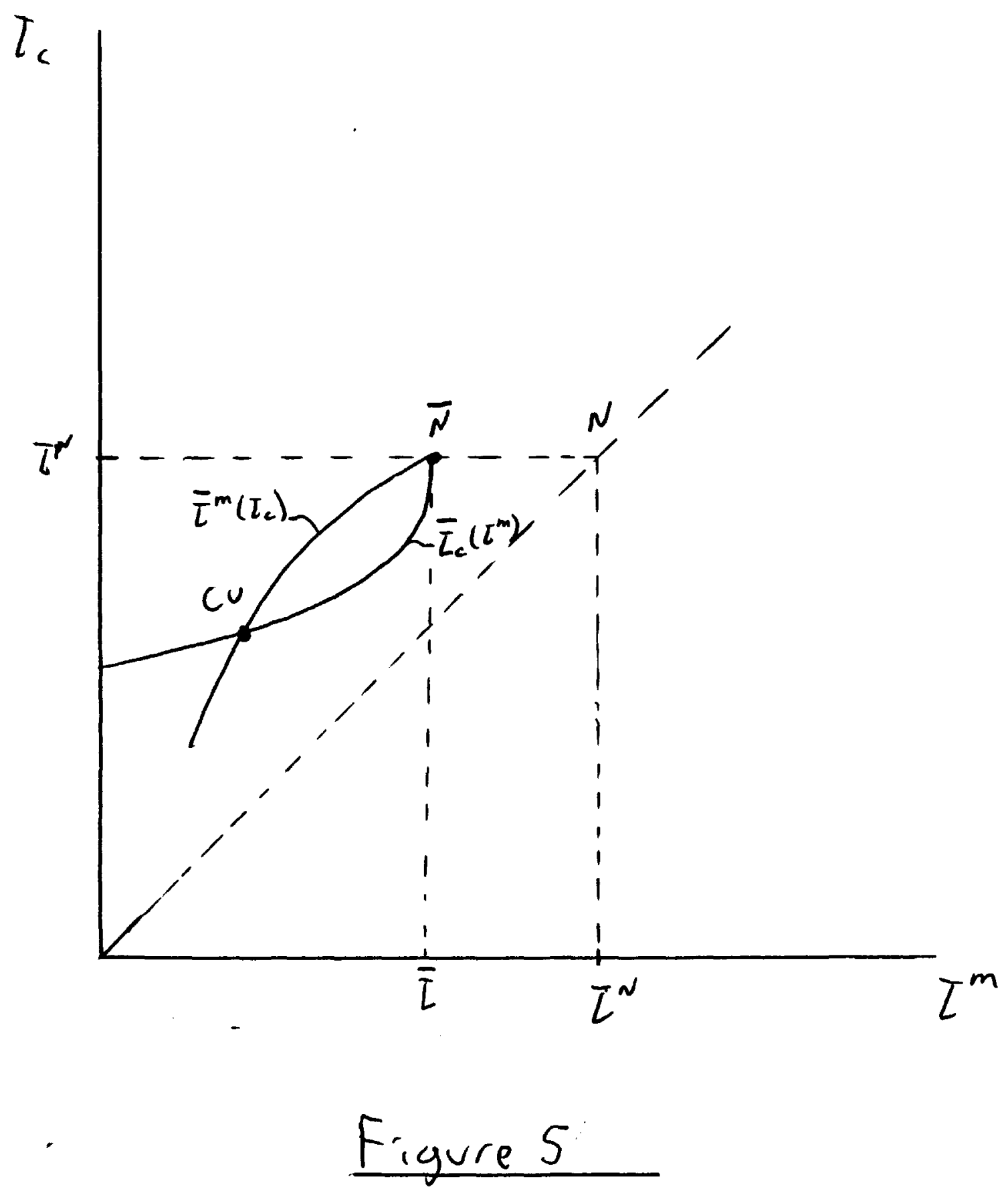




\title{
1996-1997 Discussion Paper Series
}

\author{
Department of Economics \\ Columbia University \\ 1022 International Affairs Bldg. \\ 420 West 118th Street \\ New York, N.Y., 10027
}

The following papers are published in the 1996-97 Columbia University Discussion Paper series which runs from early November to October 31 of the following year (Academic Year).

Website: $\quad$ http://www.columbia.edu/dlc/wp/econ/index.html.

You may download any papers found on this site.

\section{For Ordering Hardcopies:}

Domestic orders for discussion papers are available for purchase at the cost of $\$ 8.00$ (U.S.) Per paper and $\$ 140.00$ (US) for the series.

Eoreign orders cost $\$ 10.00$ (US) per paper and $\$ 185.00$ for the series.

To order discussion papers, please write to the Discussion Paper Coordinator at the above address along with a check for the appropriate amount, made payable to Department of Economics, Columbia University. Please be sure to include the series number of the requested paper when you place an order. 
9697-01 Fertility Behavior Under Income Uncertainty

9697-02 Trade Restrictions, imperfect Competition and National Welfare with Foreign Capital Inflows

9697-03 Restructuring an Industry during Transition: a Two-Priced Model

9697-04 A Conformity Test for Cointegration

9697-05 Low-Wage Employment Subsidies in a Labor-Turnover Model of the 'Natural Rate' (November 1996)

9697-06 The Knowledge Revolution

9697-07 The Role of Absolute Continuity in "Merging Opinions" and "Rational Learning"

9697-08 The Soviet Bloc and the Soviet Union: Why did they fall apart?

9697-09 Regionalism and Multilateral Tariff Cooperation

9697-10 Supplier Relations and the Market Context: A theory of handshakes

9697-11 Vertical Foreclosure with the Choice of Input Specifications

9697-12 Equilibrium Vertical Foreclosure with Investment by: P. Ranjan

by: P. Ranjan

by: R. Ericson

by: P. Dhrymes

by: H.T. Hoon

E. Phelps

by: G. Chichilnisky

by: R. Miller C.W. Sanchirico

by: P. Desai

by: K. Bagwell

R. Staiger

by: J. McLaren

by: J.P. Choi

S. Yi

by: J.P. Choi

S. Yi 